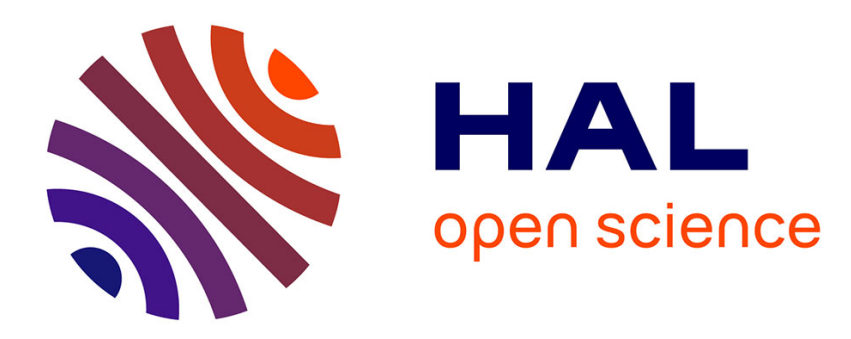

\title{
Sub-metropolitan Tax Competition with Household and Capital Mobility
}

Tidiane Ly

\section{To cite this version:}

Tidiane Ly. Sub-metropolitan Tax Competition with Household and Capital Mobility. 2016. halshs01349869

\section{HAL Id: halshs-01349869 \\ https://shs.hal.science/halshs-01349869}

Preprint submitted on 29 Jul 2016

HAL is a multi-disciplinary open access archive for the deposit and dissemination of scientific research documents, whether they are published or not. The documents may come from teaching and research institutions in France or abroad, or from public or private research centers.
L'archive ouverte pluridisciplinaire HAL, est destinée au dépôt et à la diffusion de documents scientifiques de niveau recherche, publiés ou non, émanant des établissements d'enseignement et de recherche français ou étrangers, des laboratoires publics ou privés. 
UMR 5824

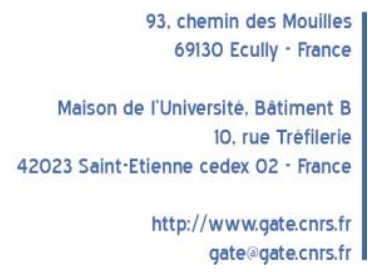

WP 1624 - July 2016

\title{
Sub-metropolitan Tax Competition with Household and Capital Mobility
}

Tidiane Ly

\begin{abstract}
:
This paper investigates the efficiency properties of tax competition between submetropolitan jurisdictions when capital, residents and workers are mobile, and both households and firms compete for local land markets. We analyze two decentralized equilibria: (1) with a local tax on residents and two separate local taxes on capital and land inputs, efficiency is achieved and the existence of a marginal fiscal cost due to residents' mobility is revealed; (2) combination of the taxes on capital and land inputs into a single business property tax leads local authorities to charge inefficiently high taxation on capital. We show that capital mobility induces a reduction in the business land taxation and local public inputs are used to offset the distorting effects of the property tax, accounting for the distorting impact of workers' mobility.
\end{abstract}

\section{Keywords:}

Tax competition, Mobility, Public goods, Public inputs

JEL codes:

$\mathrm{H} 71, \mathrm{H} 72$, R50, R51

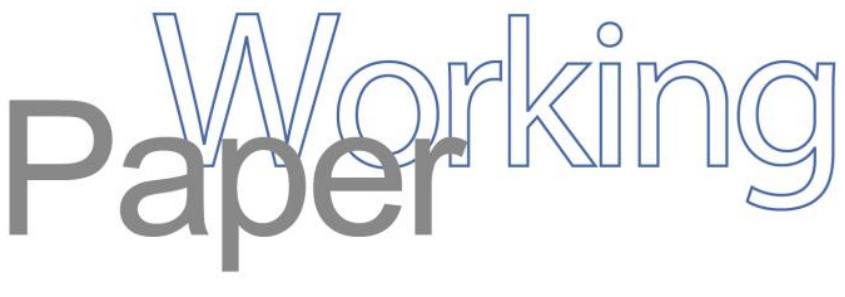




\title{
Sub-metropolitan Tax Competition with Household and Capital Mobility
}

\author{
Tidiane Ly* \\ GATE Lyon Saint-Etienne
}

July 2016

\begin{abstract}
This paper investigates the efficiency properties of tax competition between submetropolitan jurisdictions when capital, residents and workers are mobile, and both households and firms compete for local land markets. We analyze two decentralized equilibria: (1) with a local tax on residents and two separate local taxes on capital and land inputs, efficiency is achieved and the existence of a marginal fiscal cost due to residents' mobility is revealed; (2) combination of the taxes on capital and land inputs into a single business property tax leads local authorities to charge inefficiently high taxation on capital. We show that capital mobility induces a reduction in the business land taxation and local public inputs are used to offset the distorting effects of the property tax, accounting for the distorting impact of workers' mobility.
\end{abstract}

Keywords: Tax competition; Mobility; Public goods; Public inputs JEL: H71; H72; R50; R51

*Univ Lyon, CNRS, GATE UMR 5824, F-69130, ECULLY, France. Email: ly@gate.cnrs.fr

I thank Sonia Paty, Florence Goffette-Nagot, Hubert Jayet, Stéphane Riou and Thierry Madiès, for comments and suggestions on earlier drafts. I also thank participants in the Political Economy and Local Public Finance Workshop (Lille), GATE (Lyon), Journées de Microéconomie Appliquée (Besançon) and French Economic Association Meeting (Nancy) for their comments. Financial support from Région Auvergne-Rhône-Alpes (ARC 7 and Explora'Doc) is gratefully acknowledged. 


\section{Introduction}

It is generally acknowleged that decentralization of many central government activities to lower levels of government is desirable if jurisdictions are linked by high mobility of households and firms. Mobility can force local authorities to take account of agents' preferences (Tiebout 1956; McLure 1986). ${ }^{1}$ This suggests the need to understand local governments' behavior in lower-level jurisdictions such as counties, municipalities, townships and districts. However, the framework provided by the traditional tax competition literature is more tailored to competition between regions or states within a federation, and little attention has been paid to the proper features of the sub-metropolitan level. The purpose of the present paper is to propose a tax competition model adapted to the specific environment of low-level jurisdictions which enables investigation of the efficiency properties of sub-metropolitan tax competition in the context of mobile capital and households.

Tax competition among sub-metropolitan governments (or municipalities) occurs within a specific context of fiscal relations which differ from those typical of upper government layers. First, the municipality-level is characterized by high levels of household interjurisdictional mobility. By comparison, individual mobility in response to short-run public policy changes is much smaller across metropolitan areas and especially across states, which is in line with the immobility hypothesis of Zodrow and Mieszkowski (1986) and Wilson (1986). This high mobility of the tax base in municipalities leads to stronger tax competition between sub-metropolitan governments. Second, competition among municipalities occurs within metropolitan areas composed of a large central jurisdiction and many small communities. While the center has some market power and therefore can behave strategically, the vast majority of municipalities are atomistic. ${ }^{2}$ In this paper, the focus is on tax competition between atomistic jurisdictions. Several recent contributions (see e.g. Janeba and Osterloh 2013; Gaigné et al. 2015) focus on core-periphery relations. ${ }^{3}$ The third and most significant specificity of municipal level is the dual nature of household mobility across jurisdictions. A mobile household typically chooses both a place of residence and a workplace, which potentially are located in two different municipalities. ${ }^{4}$ Given this specific local environment, an analysis of municipality governments decisions requires an appropriate theoretical framework.

There is a fairly large literature on the efficiency properties of federal systems when firms - or more specifically capital - and households are mobile across jurisdictions.

\footnotetext{
${ }^{1}$ See, e.g., Oates et al. (1972), Wellisch (2006) and Wildasin (2013) for discussion of the advantages and disadvantages of decentralization of public policies.

${ }^{2}$ Brülhart et al. (2015) provide strong empirical evidence of a high level of urban fragmentation within metropolitan areas (or "cities"). Atomisticity partly explains the lack of spatial interactions between municipalities found in e.g.Lyytikäinen (2012),Isen (2014) and Baskaran (2014).

${ }^{3}$ See Brülhart et al. (2015) for a comprehensive overview of this recent literature.

${ }^{4}$ See e.g. McKenzie (2013) for empirical evidence of the significance of county-to-county commuting in the United States.
} 
Early contributions were introduced by Wilson (1995), Richter and Wellisch (1996) and Brueckner (2000). See Wellisch (2006) for a comprehensive review. The simplest models involve small jurisdictions with policies that do not affect prices or utility in other jurisdictions, perfectly mobile capital and residents-workers, and a fixed land factor. ${ }^{5}$ Local governments provide congestible local public goods financed by various tax instruments. A central result is that a residence-based head tax on mobile households to internalize their congestion costs and an undistorsive tax on land to balance the local budget are sufficient to achieve Pareto efficiency of the competitive equilibrium between jurisdictions. Such an efficiency-supporting tax structure is qualified as complete. Richter and Wellisch (1996) demonstrate that with the introduction of several firms and local impure public factors this efficiency result still holds, provided that jurisdictions can raise local poll taxes on mobile firms. Inefficiencies occur whenever one of these tax instruments is unavailable or is replaced by a distortive tax. ${ }^{6}$

While the above contributions differ in important respects, they all assume that mobile individuals work in their chosen residential location, and consequently, they treat wage as a jurisdiction-specific variable. This makes the above models appropriate to study tax competition between large jurisdictions such as regions or states. ${ }^{7}$ However, as Braid (1996) notes, within a metropolitan area, having decided on a residential location, households can commute to work anywhere in the metropolis, which equalizes wages across jurisdictions. In Braid's model, sub-metropolitan jurisdictions compete for mobile capital and workers, but residents are assumed to be immobile. Conversely, Hoyt (1991), Krelove (1993) and Wilson (1997) employ the model developed originally by Epple and Zelenitz (1981) and Henderson (1985) to study the policy choices of sub-metropolitan governments when households are free to choose their residential location; however, these works ignore the location of labor and businesses.

This paper extends the tax competition model with residents'-workers' mobility developed by Wilson (1995) and Richter and Wellisch (1996) (WRW hereafter) and investigates the efficiency properties of tax competition between sub-metropolitan jurisdictions when capital and households are mobile. There are two main features that distinguish our model from the models in the literature. First, previous studies focus on workers',

\footnotetext{
${ }^{5}$ While this paper is interested in households' perfect mobility, which may be relevant at the municipal level, other papers which investigate regional tax competition focus on imperfectly mobile households. Based on the model proposed by Mansoorian and Myers (1993), several authors, such as Burbidge and Myers (1994) and Wellisch (1994), study tax competition when individuals have different degrees of home attachment. Bucovetsky (2011) studies the situation where households face a fixed uniform mobility cost when moving from one jurisdiction to another.

${ }^{6}$ Wilson (1995) demonstrates that contrary to head taxes on households, labor taxes on individual labor supply induce underprovision of public goods. Using Richter and Wellisch (1996)'s framework, Wellisch and Hulshorst (2000) analyze the distortions induced by the absence of either an undistortive tax on land or one of the direct taxes on households and firms.

${ }^{7}$ Mieszkowski and Zodrow (1989) refer to this type of models as regional models, whereas they qualify as metropolitan models, those that study tax competition within a metropolitan area.
} 
residents' or workers'-residents' mobility; the framework proposed here integrates both residents' and workers' mobility as separate household choices. In lower-level jurisdictions, this is empirically more relevant, and allows clarification of the role of each market from the perspective of the local authorities. ${ }^{8}$ The second and most important characteristic of this model is the presence of a common land market for households and firms; the previous literature which considers both households' and firms' mobility, sees land use as confined to firms. Specifically, in contrast to the WRW model which focuses on labor markets, in low-level jurisdictions the interactions of interest between mobile households and firms takes place in local land markets through land rent adjustments. The other features of the model are standard. A federation consisting of a large number of small jurisdictions is considered. Like residents and workers, capital is perfectly mobile throughout the federation, while each jurisdiction is endowed with a fixed amount of land. Each household owns an equal share of the federation's total capital and land endowments. Local authorities provide congestible public goods and pure public inputs financed by endogenous multiple tax instruments.

Two decentralized equilibria are studied in this paper. In the first, local governments are assumed to finance public expenditure by the levying of a residence-based head tax on households and two source-based taxes on firms - a business capital tax, and a business land tax. ${ }^{9}$ In the WRW framework, since all land serves as an input, the business land tax which relies on a fixed factor, is undistortive. Thus the tax structure is complete, a congestion fee is raised on households, capital is not taxed, and public services are provided efficiently. ${ }^{10}$ This paper extends these findings allowing mobile residents also to consume land, so that business land use becomes endogenous. Although each separate tax is now distortive, the overall tax structure remains complete. A noteworthy change in the first-best tax policy however occurs. To control the size of its residential population, a jurisdiction needs to increase the head tax to above the marginal crowding cost: since new residents necessarily replace firms on the local land market, and thereby erode the business land tax base, they involve an additional marginal cost that also needs to be internalized.

In practice, combining related tax bases saves on administration costs. ${ }^{11}$ Thus, it is

\footnotetext{
${ }^{8} \mathrm{~A}$ recent contribution by Gaigné et al. (2015) also integrates both residential and labor mobility of households. The authors develop a urban economic model with asymmetric tax competition within metropolitan areas. Contrary to the present paper which analyzes the efficiency properties of local governments behaviors when jurisdictional boundaries are fixed, Gaigné et al. (2015)'s study focuses on the optimal structure of metropolitan areas. Thus, their results should be regarded as complementary to those in this paper.

${ }^{9}$ Business taxes are source-based since both local inputs are partially owned by non-residents.

${ }^{10}$ This corresponds to the first-best case in Wilson (1995). Similar outcomes are obtained by Wellisch and Hulshorst (2000) in Richter and Wellisch's (1996) framework with several firms involving congestion but no capital. In their framework, due to firms congestion, the optimal poll business tax is a congestion fee.

${ }^{11}$ Hettich and Winer $(1988,1999)$ characterize the optimal number of activities within a tax base, accounting for the administrative and political costs. Another rationale for a combined tax is that it
} 
common for statutory restrictions to require local authorities to levy a single business property tax rate on both capital and land inputs. ${ }^{12}$ Introducing a combined business property tax appears to be a natural departure from the first-best tax structure (e.g. Wilson 1984, 1995; Braid 1996). In the second decentralized equilibrium analyzed in this paper, local governments may freely choose the levels of a single business property tax levied on both capital and land inputs, and a head tax on residents. Our analysis provides two new insights. First, the only tax distortion caused by the property tax is an inefficiently low taxation of business land in order to attract mobile capital. Due to the interactions between households and firms in local land markets, local authorities do not need to compensate for this decline by increasing their tax on residents, which contrasts with findings in the WRW framework. ${ }^{13}$ Second, this paper extends Wilson's (1995) focus on local public goods, to include local public inputs, and provides an optimal second-best provision rule which reveals that local public inputs are provided so as to balance the locational distortions caused by the property tax. It highlights the key role of workers's mobility in the choice of the local public input supply. ${ }^{14}$

Beyond the current analysis, the proposed model provides a basis from which to examine the efficiency properties of various possible local tax systems; as such, it can be relied on to address a number of issues related to optimal taxation in sub-metropolitan jurisdictions in a decentralization context. In addition, our analysis suggests the need for more empirical investigations of business property tax limitation reforms. Several reforms resulting in capital being drastically limited or removed from the local combined property tax base have been implemented in the United States (Ohio, 2005; Michigan, 2014) and in Europe (France, 2010). Empirical investigation of their impact on the local tax mix and local provision of public services would provide new insights into tax competition at the sub-metropolitan level.

The paper is organized as follows. Section 2 specifies the general model. Section 3 characterizes efficient allocation in a metropolitan area and derives a baseline efficiencysupporting tax system. Section 4 studies decentralized competitive equilibria with a complete tax instrument set, and with a combined business property tax. Section 5 concludes.

might be difficult, in practice, to disentangle closely related tax bases. For instance, land improvements which constitute a type of capital, are often integrated in the land tax base (Fisher, 2015).

${ }^{12}$ E.g. in the United States the legal restrictions in 40 out of the 50 states impose equal rates on real property (land and buildings) and personal property (equipment, machinery, inventories...). (Source: the online database published by the Lincoln Institute of Land Policy, 2014).

${ }^{13}$ When regional authorities are constrained to use a combined business property tax, Wilson (1995) shows that the distortions are balanced among all their tax instruments.

${ }^{14}$ This provision rule is in line with the results in Matsumoto and Sugahara (2014). Their framework differs in several respects from the one proposed here, but the main difference is that we account for the existence of an untaxed mobile factor (labor). 


\section{The model}

\subsection{The economy}

Consider a federation, which can be regarded as a metropolitan area, consisting of $n$ sub-metropolitan jurisdictions indexed by $i=1, \ldots, n$. The federation is exogenously endowed with $\mathcal{K}$ units of capital. Its fixed total population is denoted $\mathcal{P}$. Each jurisdiction $i$ is endowed with a fixed land supply $\mathcal{L}_{i}$, is inhabited by $R_{i}$ mobile residents, and hosts $W_{i}$ mobile workers, such that

$$
\mathcal{P}=\sum_{i=1}^{n} R_{i}, \quad \text { (2.1a) } \mathcal{P}=\sum_{i=1}^{n} W_{i},
$$

Note that equations (2.1) make explicit a first distinguishing feature of this framework: each of the $R_{i}$ residents in jurisdiction $i$ potentially could work in another jurisdiction, so that $R_{i}$ and $W_{i}$ do not necessarily coincide at the level of jurisdiction $i$ which contrasts to what is postulated in the WRW framework. Relaxing this assumption allows us to account for the fact that within a metropolitan area, residential location and workplace decisions are separated.

Firms in community $i$ produce a private numeraire good which can be consumed anywhere in the metropolis. The production technology in jurisdiction $i$ is described by the well-behaved production function $F^{i} \equiv F\left(W_{i}, K_{i}, L_{i}, z_{i}\right)$, where the three private factors $W_{i}, K_{i}$ and $L_{i}$ respectively correspond to labor, capital and land, while $z_{i}$ is the public input provided by community $i . F^{i}$ exhibits constant returns to scale in private factors. ${ }^{15}$ Marginal products are positive and decreasing, and all factors are assumed to exhibit two-by-two technological complementarity so that cross derivatives of $F^{i}$ are positive. ${ }^{16}$ Since all capital is used in the federation, we have

$$
\mathcal{K}=\sum_{i=1}^{n} K_{i}
$$

Each resident of community $i$ derives utility from private consumption, a congestible public good and one unit of land, which is inelastically demanded in the individual's jurisdiction of residence. ${ }^{17}$ Thus, a resident is characterized by the utility function $U^{i} \equiv$

\footnotetext{
${ }^{15}$ Making the alternative assumption that $F^{i}$ exhibits constant returns to scale in all factors including the public input would not affect significantly the analysis in this paper, since the number of firms is normalized to one (see Matsumoto, 1998). The case of constant returns to scale in private factors is chosen for convenience and is usually considered as the empirically more relevant case (see footnote 45).

${ }^{16}$ The usual assumption that factors are complement in production is reasonable given the aggregation of production.

${ }^{17}$ For the sake of simplicity, we do not consider housing construction so that households and firms use land directly, and we assume that the individual demand for land is inelastic. In Hoyt (1991), Krelove (1993) and Wilson (1997), housing production uses mobile capital and fixed land, and the individual housing demand is elastic. Krelove shows that housing taxation entails usual distortions from optimal commodity tax theory. See Wilson (2003) for a survey of this literature.
} 
$U\left(x_{i}, g_{i}, R_{i}\right)$, where $x_{i}$ denotes private consumption, and $g_{i}$ is the level of congestible public good provided by community $i$. $U^{i}$ is assumed to be increasing in the first two arguments, and decreasing in $R_{i}$ due to congestion. ${ }^{18}$ The total cost function of providing the local public good and input in community $i$ is denoted by $C^{i} \equiv C\left(g_{i}, z_{i}\right)$ which is and expressed in units of the private good. Marginal costs are positive and nondecreasing.

To complete the description of the economy, since no vacant land is allowed, in each jurisdiction $i$ we have

$$
\mathcal{L}_{i}=R_{i}+L_{i}
$$

The land use condition (2.3) reveals the second distinguishing characteristic of this framework. ${ }^{19}$ In the WRW model, since households do not consume land, firms use the entire local land as an input so that the model incorporates a fixed factor. In the economy considered here, this assumption is relaxed and all private factors - labor, capital and land - are variable.

\subsection{Private behavior}

Households, both as residents and workers, are assumed to be perfectly mobile within the federation. As residents, households decide on a location which will maximize their utility. They incur no mobility cost so that free migrations equate utility levels across jurisdictions:

$$
U\left(x_{i}, g_{i}, R_{i}\right)=U\left(x_{j}, g_{j}, R_{j}\right)
$$

for all $i, j$ in $\{1, \ldots, n\}$.

As a worker, each individual is endowed with one unit of labor, inelastically supplied in the jurisdiction of the federation which offers the highest wage. Costless commuting entails that the same exogenous wage $w$ prevails throughout the federation. ${ }^{20}$ Moreover, each resident of the federation possesses an identical fraction of the total capital endowment $\mathcal{K}$ which she invests in the jurisdiction where she receives the highest return. Since capital is perfectly mobile across jurisdictions, in equilibrium the same return to capital $r$ prevails across the whole federation. Also, land ownership is shared equally among all metropolis residents. From the perspective of a small jurisdiction, the wage rate $w$ and the capital return $r$ are exogenous. However, since local land endowments are fixed,

\footnotetext{
${ }^{18}$ Empirical evidence of congestion are provided in Borcherding and Deacon (1972) and Bergstrom and Goodman (1973). See also McMillan et al. (1981) and Edwards (1990).

${ }^{19}$ Notice also that there may be differences in local land endowments $\mathcal{L}_{i}$. This paper is in fact not restricted to the study of symmetric equilibria across jurisdictions.

${ }^{20}$ Commuting is a noticeable departure from the WRW framework in which costless commuting is not allowed. Thus, in the WRW model, the benefits of local policies capitalize into the wage rate which is an endogenous jurisdiction-specific variable. This explains the central role of local labor markets in this literature.
} 
the land rent $\rho_{i}$ is endogenous and specific to jurisdiction $i$. All prices are expressed in terms of the numeraire good. Based on the above, the real income of an individual is

$$
y=w+\frac{r \mathcal{K}+\sum_{i=1}^{n} \rho_{i} \mathcal{L}_{i}}{\mathcal{P}}
$$

which indicates that the individual income is independent of the jurisdiction of residence. Households use their income to consume the private good $x_{i}$ and their one-unit land use, paying the land rent $\rho_{i}$. The local government $i$ collects a residence-based head tax $\tau_{i}^{R}$. Because individuals consume a single unit of land, $\tau_{i}^{R}$ can be interpreted either as a unit tax on land consumption or as a head tax. The budget constraint of a representative resident of jurisdiction $i$ can be written as

$$
x_{i}+\rho_{i}=y-\tau_{i}^{R}
$$

Firms choose labor $W_{i}$, capital $K_{i}$ and land $L_{i}$ as to maximize profits $F^{i}-w W_{i}-$ $\left(r+\tau_{i}^{K}\right) K_{i}-\left(\rho_{i}+\tau_{i}^{L}\right) L_{i}$, where $\tau_{i}^{K}$ and $\tau_{i}^{L}$ are respectively the unit taxes on capital and business land use in community $i{ }^{21}$ Factor prices and taxes are taken as given by firms. Profit maximization implies

$$
\begin{aligned}
& F_{W}^{i}=w \\
& F_{K}^{i}=r+\tau_{i}^{K}, \\
& F_{L}^{i}=\rho_{i}+\tau_{i}^{L},
\end{aligned}
$$

that is, firms' competitive behavior equalizes marginal factor products and factor prices. Constant returns to scale result in

$$
F^{i}-w W_{i}-\left(r+\tau_{i}^{K}\right) K_{i}-\left(\rho_{i}+\tau_{i}^{L}\right) L_{i}=0
$$

which means that there is no profit opportunity at equilibrium.

The local public sector must satisfy the following budget constraint:

$$
\tau_{i}^{R} R_{i}+\tau_{i}^{K} K_{i}+\tau_{i}^{L} L_{i}=C\left(g_{i}, z_{i}\right)
$$

that is, tax revenues collected from residents, business capital and business land use must cover the costs of public services provision.

\section{Pareto efficiency}

Before studying potential distortions of decentralization, we derive a baseline Paretoefficient allocation of production factors, households and public services within the federation. Since we are interested in allocations that are compatible with costless migrations

\footnotetext{
${ }^{21}$ For reasons of space the framework does not consider local taxes on labor inputs. However, as discussed below, the results can easily be extended to labor taxes.
} 
of residents, the central planner's choice has to rule out interjurisdictional utility differentials. ${ }^{22}$ Therefore, the planner's program consists of choosing a feasible allocation which maximizes utility in a jurisdiction, say 1 , under the resource constraints (2.1)-(2.3) and the migration equilibrium condition (2.4):

$$
\text { maximize } U\left(x_{1}, g_{1}, R_{1}\right)
$$

choosing $x_{i}, g_{i}, z_{i}, R_{i}, W_{i}, K_{i}$ and $L_{i}$ subject to (2.1)-(2.4) and

$$
\sum_{i=1}^{n} F\left(W_{i}, K_{i}, L_{i}, z_{i}\right)=\sum_{i=1}^{n}\left[R_{i} x_{i}+C\left(g_{i}, z_{i}\right)\right],
$$

where condition (3.1) is the feasibility constraint of the economy: global output has to cover households' private consumption and the costs of providing public services.

It is straightforward to prove that the necessary conditions for the central planner's problem then result in

$$
\begin{aligned}
& R_{i} \frac{\left|U_{R}^{i}\right|}{U_{x}^{i}}+F_{L}^{i}+x_{i}=R_{j} \frac{\left|U_{R}^{j}\right|}{U_{x}^{j}}+F_{L}^{j}+x_{j}, \\
& F_{K}^{i}=F_{K}^{j}, \\
& F_{W}^{i}=F_{W}^{j}, \\
& R_{i} \frac{U_{g}^{i}}{U_{x}^{i}}=C_{g}^{i}, \\
& F_{z}^{i}=C_{z}^{i},
\end{aligned}
$$

for all $i, j$ in $\{1, \ldots, n\}$,

where subscripts stand for derivatives and $|$.$| denotes absolute value. { }^{23}$ Rules (3.2), (3.3) and (3.4) define the efficient allocations of residents, capital and workers across jurisdictions. Condition (3.2) states that the efficient residential allocation of individuals across jurisdictions requires that the costs of a marginal resident are equalized among communities. There are three kinds of such costs. ${ }^{24}$ First, when entering a jurisdiction, a new resident decreases the utility of all residents in $i$ due to congestion: $R_{i}\left|U_{R}^{i}\right| / U_{x}^{i}$. Second, she replaces a unit of business land and thus, reduces the jurisdiction's output by $F_{L}^{i}$. Third, she consumes $x_{i}$ units of the private good. Unlike residents, marginal capital and workers involve benefits, their marginal products $F_{K}^{i}$ and $F_{W}^{i}$ but no cost. According to condition (3.3) and (3.4), the efficient allocations of capital and labor require that their respective marginal benefits are equalized among jurisdictions. Conditions (3.5) and

\footnotetext{
${ }^{22}$ This approach considers that the social planner cannot directly control migrations and is consistent with most studies with household mobility (e.g. Myers and Papageorgiou 1993; Richter and Wellisch 1996; Wellisch 2006; Wildasin 2013).

${ }^{23} \mathrm{An}$ appendix is available from the author upon request detailing the derivations of (3.2)-(3.6).

${ }^{24}$ Alternatively, as shown by the land market clearing condition (2.3), condition (3.2) also characterizes the efficient location of business land.
} 
(3.6) characterize the efficient supplies of local public services. According to condition (3.5), the efficient provision of the local public good $g_{i}$ satisfies the usual Samuelson condition: the sum of the marginal willingness to pay for the local public good of $i$ 's residents (on the left-hand side - LHS) equates to its marginal cost (on the on the righthand side - RHS). As stated by condition (3.6), a similar requirement characterizes the efficient level of public input: the marginal product of the public input on the RHS must be equal to its marginal cost on the LHS.

The efficient allocation characterized in (3.3)-(3.5) highlights several features of lowlevel jurisdictions which are essential for this analysis. At first, conditions (3.2) and (3.4) show that residents and workers assume very different roles at the sub-metropolitan level. On the one hand, new residents in a jurisdiction entail only social and economic costs since they conduct no local productive activity. On the other hand, inflows of new workers, who do not consume public goods, bring nothing but benefits - from a jurisdiction perspective, labor plays a role similar to that of capital. ${ }^{25}$ Another distinguishing characteristic of the sub-metropolitan level is highlighted by the presence of the marginal product $F_{L}^{i}$ in (3.2). It is specific to the interaction among households and firms through their use of a common local land. Thus, in contrast to the WRW model, even in the absence of congestion, residents are still costly from the jurisdiction's viewpoint. This is expected to increase the incentive for the local authorities to levy higher taxes on residents to internalize this specific marginal opportunity cost. This is explored further in section 4 .

The above characterization of efficient allocation was derived assuming that the central planner's choices replace the agents decision-making process. Although enlightening from a theoretical point of view, the efficiency conditions obtained in this way can hardly be compared with the outcomes of decentralized equilibria in which local authorities cannot directly control the economic variables. Thus, suppose now that the central planner aims to implement the efficient allocation characterized in (3.2)-(3.6), choosing $\left(\tau_{i}^{R}, \tau_{i}^{K}, \tau_{i}^{L}, g_{i}, z_{i}\right)_{i \in \llbracket 1, n \rrbracket}$ and accounting for the private behaviors described in section 2. The efficiency conditions change to:

\footnotetext{
${ }^{25}$ This should be compared to the case of higher-level jurisdictions. In this case, conditions (3.2) and (3.4) are merged, reflecting the fact that residents are not only costly but also generate some local benefits through their marginal productivity $F_{W}^{i}$ (e.g. Richter and Wellisch, 1996).
} 
Result 1. Efficient local tax system and public services provision, in a metropolitan area where the public policy instruments set $\left\{\tau_{i}^{R}, \tau_{i}^{K}, \tau_{i}^{L}, g_{i}, z_{i}\right\}$ is available, are characterized by

$$
\begin{aligned}
& \tau_{i}^{R}-R_{i} \frac{\left|U_{R}^{i}\right|}{U_{x}^{i}}-\tau_{i}^{L}=\tau_{j}^{R}-R_{j} \frac{\left|U_{R}^{j}\right|}{U_{x}^{j}}-\tau_{j}^{L}, \\
& \tau_{i}^{K}=\tau_{j}^{K} \\
& R_{i} \frac{U_{g_{i}}^{i}}{U_{x}^{i}}=C_{g}^{i}, \\
& F_{z}^{i}=C_{z}^{i},
\end{aligned}
$$

and business land taxes $\tau_{i}^{L}$ are set so as to clear the local budget restrictions (2.11),

$$
\text { for all } i, j \text { in }\{1, \ldots, n\} \text {. }
$$

Proof. See Appendix A.

According to condition (3.7), an efficient location of residents and business land within the federation requires that the net marginal benefits of residents between jurisdictions are equalized. When entering community $i$, a new resident brings in $\tau_{i}^{R}$ additional tax revenues but generates a congestion cost $R_{i}\left|U_{R}^{i}\right| / U_{x}^{i}$ and a marginal fiscal $\operatorname{cost} \tau_{i}^{L}$. This second cost stems from the crowding out of a unit of business land by the new resident which reduces the tax revenues from $\tau_{i}^{L}$. The marginal fiscal cost of households which is a central aspect of the present study, reflects the specific interaction of households and firms on local land introduced - similar to the $F_{L}^{i}$ term in (3.2). Condition (3.7) thus extends the net marginal benefits equalization rule for efficient location of residents derived in the WRW model (Wellisch, 2006). Similarly, condition (3.8) states that for capital to locate efficiently, the net marginal benefits of capital location have to be equalized across jurisdictions. Since capital involves no marginal cost, efficiency requires a uniform taxation of capital throughout the federation. ${ }^{26}$ Finally, conditions (3.9) and (3.10) simply restate the Samuelson rules for efficient public services provision.

Thus, an efficient allocation can be achieved provided that local governments behave according to the conditions derived in Result 1. However, it remains an open question to what extent decentralized local governments decisions do lead to efficiency. Section 4 addresses this issue.

\section{Decentralized equilibria with multiple tax instruments}

In order to analyze the efficiency properties of decentralized equilibria when local governments choose their tax policies and their supply of local public services, we consider a

\footnotetext{
${ }^{26}$ Notice that the symmetric role of capital and labor in this economy allows one to deduce that any uniform level of local labor tax would ensure an efficient location of workers across jurisdictions. This requirement is met since the absence of a labor tax can be considered a uniform zero-tax on labor.
} 
metropolis comprised of a large number, $n$, of atomistic jurisdictions. Thus, any jurisdiction perceives the choices made in other communities as independent of its own decisions. In the sequel, attention is focused on a representative jurisdiction $i$. In subsection 4.1, local governments behavior is specified. Subsection 4.2 characterizes optimal local public policies when the tax instrument set is comprised of three taxes on respectively residents, capital and business land use. In subsection 4.3 a decentralized equilibrium in which the two latter taxes are replaced by a single business property tax on both capital and business land use is analyzed.

\subsection{Local governments behavior}

\subsubsection{Location decisions}

Household and capital locations are not under the direct control of local government. However, a rational government must take account of location responses to its policy. The first analytical step then is to characterize the decentralized location decisions of households and capital from the perspective of jurisdiction $i$. It might be helpful at this stage to review the model variables: $\left\{\rho_{i} ; W_{i} ; R_{i} ; L_{i} ; K_{i}\right\}$ are endogenous economic variables in jurisdiction $i ;\left\{\tau_{i}^{R} ; \tau_{i}^{K} ; \tau_{i}^{L} ; g_{i} ; z_{i}\right\}$ are control variables for local government $i ;\left\{\mathcal{L}_{i} ; w ; r ; \mathcal{P}\right\}$ are exogenous from jurisdiction $i$ 's perspective where $\mathcal{L}_{i}$ is the land endowment specific to jurisdiction $i, w$ and $r$ are the prices prevailing in the entire metropolis, and $\mathcal{P}$ is the federal population. Finally, for community $i$ $\left\{\rho_{j} ; W_{j} ; R_{j} ; L_{j} ; K_{j} ; \tau_{j}^{R} ; \tau_{j}^{K} ; \tau_{j}^{L} ; g_{j} ; z_{j} ; \mathcal{L}_{j}\right\}$ are exogenous if $j \neq i$.

In equilibrium, households are indifferent between residing in community $i$ or in some other community $j$. Thus, utility is further equated across jurisdictions. Integrating the household's budget constraint (2.6) into the free mobility condition (2.4), it follows that from jurisdiction $i$ 's viewpoint, a migration equilibrium is defined by the $n-1$ bilateral relations:

$$
\begin{gathered}
U\left(y-\rho_{i}-\tau_{i}^{R}, g_{i}, R_{i}\right)=U\left(y-\rho_{j}-\tau_{j}^{R}, g_{j}, R_{j}\right) \\
\text { for all } j=1, \ldots, n \text { such that } j \neq i,
\end{gathered}
$$

where $y$ is as defined by (2.5). The presence of the individual's income on the RHS of (4.1) shows that decisions made in jurisdiction $i$ affect the level of utility enjoyed by its residents whether they continue to reside in $i$ or move to some other community $j$. Wherever a resident chooses to settle, she will still own her initial share $\mathcal{L}_{i} / \mathcal{P}$ of jurisdiction $i$ 's land endowment. Hence, any variation in the local land rent $\rho_{i}$ will affect her income, and thereby her welfare, regardless of her location. However, since the equilibrium bundle $(x, g, R)$ usually differs between jurisdictions, a given change in $\rho_{i}$ will have a different effect on the utility of a resident initially living in $i$ depending on the jurisdiction chosen for relocation. ${ }^{27}$ These differentiated income effects might

\footnotetext{
${ }^{27} \mathrm{~A}$ given increase (decrease) in the individual's income will, ceteris paribus, increase (reduce) the
} 
make it technically demanding to characterize households' location responses to local policy changes. However, they are fairly peripheral to this analysis since they are not a major determinant of households' location choices in practice. Therefore, the following analysis is restricted to the reasonable case where any such effects are ignored by mobile households:

Assumption 1. The function $U$ satisfies the following condition: $\frac{\partial U}{\partial x}(x, g, R)=$ $\frac{\partial U}{\partial x}\left(x^{\prime}, g^{\prime}, R^{\prime}\right)$, for all bundles $(x, g, R)$ and $\left(x^{\prime}, g^{\prime}, R^{\prime}\right)$ such that $U(x, g, R)=U\left(x^{\prime}, g^{\prime}, R^{\prime}\right)$.

An example of utility function which satisfies the above assumption is the common class of additively-separable functions, $U(x, g, R)=x+v(g, R) .{ }^{28}$ Assumption 1 guarantees that any marginal change in the individual's income has a neutral effect on the migration equilibrium (4.1). That is, mobile residents perceive that income, and therefore the utility prevailing in other jurisdictions, are exogenous. In formal terms, to derive population reactions to its policy, local government $i$ considers the following modified migration equilibrium condition:

$$
U\left(\bar{y}-\rho_{i}-\tau_{i}^{R}, g_{i}, R_{i}\right)=\bar{u},
$$

where $\bar{y}$ and $\bar{u}$ are some exogenous variables from the representative jurisdiction's viewpoint. Thus, the responses of capital $K_{i}$, residents $R_{i}$ and workers $W_{i}$ to changes in local government's policy instruments $\tau_{i}^{R}, \tau_{i}^{K}, \tau_{i}^{L}, g_{i}$ and $z_{i}$ can be derived from the necessary conditions for the optimal demand for labor (2.7) and capital (2.8) from local firms, and the migration equilibrium condition (4.2). Inserting (2.3) and (2.9) into (2.7), (2.8) and (4.2), we obtain the following three-equation system in $K_{i}, W_{i}$ and $R_{i}$ :

$$
\begin{aligned}
& F_{W}\left(W_{i}, K_{i}, \mathcal{L}_{i}-R_{i}, z_{i}\right)-w=0, \\
& F_{K}\left(W_{i}, K_{i}, \mathcal{L}_{i}-R_{i}, z_{i}\right)-\tau_{i}^{K}-r=0, \\
& U\left[\bar{y}-F_{L}\left(W_{i}, K_{i}, \mathcal{L}_{i}-R_{i}, z_{i}\right)-\tau_{i}, g_{i}, R_{i}\right]-\bar{u}=0,
\end{aligned}
$$

where $\tau_{i} \equiv \tau_{i}^{R}-\tau_{i}^{L}$ is the tax spread between households and business land taxes. It represents the tax revenue generated by a resident net of her marginal fiscal cost. The three locational conditions (4.3), (4.4) and (4.5) allow us to derive $K_{i}, W_{i}$ and $R_{i}$ as implicit functions of $\tau_{i}, \tau_{i}^{K}, \tau_{i}^{L}, g_{i}$ and $z_{i}$.

\subsubsection{Local government objective}

Local authorities in jurisdiction $i$ are assumed to maximize the utility of a representative resident, $U\left(x_{i}, g_{i}, R_{i}\right)$. Note that despite households' perfect mobility, the community

satisfaction the residents living in the community, and especially since the equilibrium amount of the local public good is higher (lower) than private consumption - assuming diminishing marginal rate of substitution.

${ }^{28}$ Additive-separability is a widespread hypothesis in tax competition models. However, utility need not be linear in consumption. E.g., Assumption 1 holds also for $U(x, g, R)=\Phi[x+v(g, R)]$, whenever $\Phi$ is a bijective function, which is guaranteed by the usual assumptions: $\Phi$ is continuous and $\Phi^{\prime}>0$. 
perceives that it can influence the level of satisfaction of its residents since, in contrast to mobile households, local government takes account of the effects of marginal income changes on its residents' satisfaction. Since households ignore these effects when deciding on a residential location, changes in the jurisdiction's policy instruments induce variations in utility which are not offset completely by households' subsequent migrations. It follows also that the utility-maximizing local government's objective boils down to maximizing the local net land rent $\rho_{i} \mathcal{L}_{i}$, which allows us to state that:

Lemma 1. Suppose that Assumption 1 holds. If jurisdictions are small and residents are perfectly mobile, then a utility-maximizing local government aims at maximizing the net land rent in its jurisdiction.

Proof. Consider the impact of a small local policy change on the representative resident's utility. Inserting the budget constraint (2.6) into the utility function and accounting for the free mobility condition (4.2), total differentiation of $U^{i}$ yields $\mathrm{d} U^{i}=U_{x}^{i} \mathrm{~d} y+\mathrm{d} U(\bar{y}-$ $\left.\rho_{i}-\tau_{i}^{R}, g_{i}, R_{i}\right)=U_{x}^{i} \mathrm{~d} y+\mathrm{d} \bar{u}=U_{x}^{i} \mathrm{~d} y$, since $\mathrm{d} \bar{u}=0$. That is, the only channel through which policy can increase utility is income variations; residents mobility compensates for any other effect. Using the income definition (2.5), the marginal utility change can be written as $\mathrm{d} U^{i}=U_{x}^{i} \frac{\mathcal{L}_{i}}{\mathcal{P}} \mathrm{d} \rho_{i}$. Thus, any utility gain resulting from the incremental policy is due to an increase in the return to domestic landowners.

According to Lemma 1, local governments pursue a policy favoring local landowners. This is consistent with most models of tax competition among many small jurisdictions in the presence of perfect mobility of residents (e.g. Henderson 1985; Hoyt 1991; Krelove 1993; Wilson 1995; Wellisch 2006). ${ }^{29}$ In this paper, land-rent-maximizing behavior stems from household perfect mobility. However, there can be other reasons for this behavior. Following Bucovetsky (1995), it could be argued that landowners constitute a majority of the voter residents in a number of local jurisdictions. Moreover, their greater interest in the community may explain that they are more prone to lobbying local authorities compared to non-landowners.

\subsection{First-best policy}

We assume first that local governments can use three different tax instruments: a head tax on households $\tau_{i}^{R}$, a unit tax on capital $\tau_{i}^{K}$ and a unit tax on business land use $\tau_{i}^{L}$. In what follows, we assume without loss of generality that the local tax instrument set is $\left\{\tau_{i} ; \tau_{i}^{K} ; \tau_{i}^{L}\right\}$. Local public policies are thus constrained by the following budget

\footnotetext{
${ }^{29}$ The result stated in Lemma 1 requires a separation of individuals' decisions as consumers and landowners. It is ensured by the neutrality hypothesis (Assumption 1) introduced in this paper. Other approaches are also possible. For example, Wilson (1995) and Wellisch and Hulshorst (2000) assume an Arrow-Debreu separation, while Henderson (1985) assumes that the local policy is conducted by absentee landowners. Alternatively, Hoyt (1991) postulates that the policy instruments are controlled by some immobile landowners who aim at maximizing their net wealth.
} 
restriction:

$$
\tau_{i} R_{i}+\tau_{i}^{K} K_{i}+\tau_{i}^{L} \mathcal{L}_{i}=C\left(g_{i}, z_{i}\right),
$$

where the definition of $\tau_{i}$ and (2.3) are used to substitute respectively for $\tau_{i}^{R}$ and $L_{i}$ into (2.11). Written in this form, the budget constraint shows that local government $i$ considers its tax instrument set as composed of two taxes on mobile tax bases - the net tax on residents $\tau_{i}$ and the capital $\operatorname{tax} \tau_{i}^{K}$ - and a $\operatorname{tax} \tau_{i}^{L}$ levied on the fixed total land endowment. Note that the business land tax remains a distortive tax since it still alters the demand for land from local firms. However, the budget constraint (4.6) reveals that local authorities use the distortive tax on residents to offset any change in tax revenues caused by business land use variations, so that they can use $\tau_{i}^{L}$ as if it were undistortive.

Let us consider in the sequel that the local government freely chooses $\tau_{i}, \tau_{i}^{K}, g_{i}$ and $z_{i}$, while $\tau_{i}^{L}$ adjusts endogenously so as to satisfy (4.6). From Lemma 1 the objective of the local government is to maximize the local net land rent $\rho_{i} \mathcal{L}_{i}$. Using the land market clearing condition (2.3), the zero-profit requirement (2.10) and replacing $\rho_{i}$ with (2.9), local government $i$ 's objective can be rewritten as follows:

$$
\Omega_{i} \equiv \rho_{i} \mathcal{L}_{i}=F^{i}+F_{L}^{i} R_{i}-w W_{i}-\left(r+\tau_{i}^{K}\right) K_{i}-\tau_{i}^{L} \mathcal{L}_{i}
$$

Using the budget constraint (4.6) to substitute $\tau_{i}^{L}$ into (4.7), it follows that the local government's problem is to maximize

$$
\begin{array}{r}
F\left(W_{i}, K_{i}, \mathcal{L}_{i}-R_{i}, z_{i}\right)-w W_{i}-r K_{i}+\left[F_{L}\left(W_{i}, K_{i}, \mathcal{L}_{i}-R_{i}, z_{i}\right)+\tau_{i}\right] R_{i} \\
-C\left(g_{i}, z_{i}\right)
\end{array}
$$

choosing $\tau_{i}, \tau_{i}^{K}, g_{i}$ and $z_{i}$, where $W_{i}, K_{i}$ and $R_{i}$ depend on the policy instruments so as to satisfy (4.3)-(4.5). The first-order conditions for optimal local government behavior are

$$
\begin{aligned}
& \frac{d \Omega_{i}}{d t_{i}}=\left(\tau_{i}+R_{i} \frac{U_{R}^{i}}{U_{x}^{i}}\right) \frac{\partial R_{i}}{\partial t_{i}}+\tau_{i}^{K} \frac{\partial K_{i}}{\partial t_{i}}+\left(R_{i} \frac{U_{g}^{i}}{U_{x}^{i}}-C_{g}^{i}\right) \frac{\partial g_{i}}{\partial t_{i}}+\left(F_{z}^{i}-C_{z}^{i}\right) \frac{\partial z_{i}}{\partial t_{i}}=0 \quad(4.9) \\
& \text { with } t_{i} \in\left\{\tau_{i} ; \tau_{i}^{K} ; g_{i} ; z_{i}\right\}, \text { and } \frac{\partial t_{i}}{\partial t_{i}^{\prime}}= \begin{cases}1 & \text { if } t_{i}=t_{i}^{\prime} \\
0 & \text { otherwise. }\end{cases}
\end{aligned}
$$

In other words, conditions (4.9) indicate that local government $i$ chooses each policy instrument so as to equalize the marginal benefits and marginal costs it induces, while taking account of economic agents' mobility. ${ }^{30}$ The location responses of residents and capital to changes in any policy variable $t_{i}, \partial R_{i} / \partial t_{i}, \partial W_{i} / \partial t_{i}$ and $\partial K_{i} / \partial t_{i}$ can be derived by total differentiation of the locational system (4.3)-(4.5). Their signs are summarized below:

\footnotetext{
${ }^{30}$ The detailed derivation of the necessary conditions (4.9) is provided in Appendix B.
} 
Lemma 2. The equilibrium responses of residents, workers and capital to changes in the policy instruments have the following signs:

$$
\begin{aligned}
& \frac{\partial R_{i}}{\partial t_{i}}<0 \quad \text { and } \quad \frac{\partial K_{i}}{\partial t_{i}}, \frac{\partial W_{i}}{\partial t_{i}}>0, \quad \text { for } \quad t_{i} \in\left\{\tau_{i} ; z_{i}\right\}, \\
& \frac{\partial R_{i}}{\partial t_{i}}>0 \quad \text { and } \quad \frac{\partial K_{i}}{\partial t_{i}}, \frac{\partial W_{i}}{\partial t_{i}}<0, \quad \text { for } \quad t_{i} \in\left\{\tau_{i}^{K} ; g_{i}\right\} .
\end{aligned}
$$

Proof. See Appendix B, for the detailed derivation of the location responses. ${ }^{31}$

Lemma 2 depicts the way political decisions affect the location choices of mobile households and capital in equilibrium. It states that an increase in the net tax on residents induces an outflow (resp. inflow) of residents (resp. capital and labor). A decrease in public good provision has the same impact. A higher capital tax decreases (resp. increases) the equilibrium quantity of capital and labor (resp. number of residents). Decreasing the public input supply entails similar effects.

The equilibrium location responses require some comment. Notice first, that since $\tau_{i}^{L}$ does not appear in the locational system (4.3)-(4.5), changes to the business land tax have no impact on population or capital provided that the tax spread between $\tau_{i}^{R}$ and $\tau_{i}^{L}$ is unchanged. This confirms that even relaxing the hypothesis of a fixed land factor which is usual in the WRW framework, the business land $\operatorname{tax} \tau_{i}^{L}$ can still be used as an undistortive tax. Second, all responses of private inputs used by firms labor, capital and land - are in the same direction. This result follows directly from the hypothesis of technological complementarity among inputs. ${ }^{32}$ Thus, although the framework does not account explicitly for the number of firms (unlike that proposed by Richter and Wellisch (1996) for example) the intuition of firms' location is maintained. The last and essential comment highlights the main novel insight provided by this paper: whatever the instrument used, local authorities face a systematic trade-off between attracting residents, therefore driving out firms, and vice versa. This trade-off reflects the interactions of households and firms in local land markets. For example, by cutting household taxation, local government attracts new residents. This inflow exerts upward pressure on the local land rent which in turn, reduces the local demand for business land and induces capital and labor outflows. This compromise is specific to lower-level jurisdictions, and therefore is not part of the WRW model. At the regional level, where residents and workers cannot be dissociated, the flow of worker-residents usually follows the flow of firms (see e.g. Wellisch and Hulshorst, 2000).

Inserting the location responses into the necessary conditions (4.9), we obtain the following result:

\footnotetext{
${ }^{31}$ Derivation of the location responses requires that the local public good involve congestion, $U_{R}^{i}<0$, as assumed in this paper (see footnote 56). This requirement must be met since all factors are variable; in the WRW model, deriving the location responses requires the presence of a fixed production factor.

${ }^{32}$ This locational scheme of private inputs is not specific to the present framework. Lemma 1 in Braid (1996) depicts the same pattern and similar findings can be derived from Wilson's (1995) framework.
} 
Result 2. In equilibrium, under perfect interjurisdictional competition, local government $i$ chooses $\tau_{i}^{R}, \tau_{i}^{K}, \tau_{i}^{L}, g_{i}$ and $z_{i}$ in accordance with the following decision rules:

$$
\begin{aligned}
& \tau_{i}^{R}=R_{i} \frac{\left|U_{R}^{i}\right|}{U_{x}^{i}}+\tau_{i}^{L}, \\
& \tau_{i}^{K}=0, \\
& R_{i} \frac{U_{g}^{i}}{U_{x}^{i}}=C_{g}^{i}, \\
& F_{z}^{i}=C_{z}^{i},
\end{aligned}
$$

while satisfying the budget restriction (4.6), so that

$$
\tau_{i}^{L}=\frac{R_{i}}{\mathcal{L}_{i}}\left(\frac{C^{i}}{R_{i}}-R_{i} \frac{\left|U_{R}^{i}\right|}{U_{x}^{i}}\right)
$$

Proof. See Appendix C.

Conditions (4.10)-(4.13) characterize the behavior of any jurisdiction in the federation, so that the efficiency conditions (3.7)-(3.10) are satisfied in the decentralized equilibrium. Notice also that following condition (4.14), whenever the marginal congestion cost of public services $R_{i}\left|U_{R}^{i}\right| / U_{x}^{i}$ exceeds the per capita cost $C^{i} / R_{i}$, the business land tax is negative and thus, becomes a subsidy, and the tax on residents can be charged at below the marginal congestion cost according to condition (4.10). However, it is well known that when provision of local public services entails marginal costs that exceed average costs, private markets are expected to supply local public services efficiently (Boadway, 1980). ${ }^{33}$ This paper focuses on public services which require a public supply:

Assumption 2. (scale economies) The marginal congestion cost is lower than the average cost of local public goods, so that $R_{i}\left|U_{R}^{i}\right| / U_{x}^{i}<C^{i} / R_{i}$.

Assumption 2 is common in tax competition models dealing with household mobility. ${ }^{34}$ It implies that an efficient tax instrument set cannot be reduced to a head tax on residents: in order to dedicate this tax to controlling their population size, local governments need another instrument to finance public services. This is precisely the role of the business land tax $\tau_{i}^{L}$, as apparent in condition (4.14). ${ }^{35}$ Nonetheless, due to the trade-off faced by local authorities between hosting households and hosting firms (Lemma 2), $\tau_{i}^{L}$ also constitutes an additional cost for welcoming new residents. According to condition (4.10), local governments have incentives to choose household taxation

\footnotetext{
${ }^{33}$ The proof of this common result adapted to the present framework is available in an additional appendix, available from the author upon request.

${ }^{34}$ See e.g. Wilson (1995), Richter and Wellisch (1996) and Wellisch and Hulshorst (2000).

${ }^{35}$ The $R_{i} / \mathcal{L}_{i}$ term in $(4.14)$ - which can be written also as $1-L_{i} / \mathcal{L}_{i}$ - simply recalls that from a budgetary perspective, broadening a tax base allows to lower the related tax rate. However, this budgetary effect is of minor importance to this analysis.
} 
in order to internalize the two marginal costs involved by an additional resident: the congestion cost $R_{i}\left|U_{R}^{i}\right| / U_{x}^{i}$ and the marginal fiscal opportunity cost $\tau_{i}^{L}$ caused by the erosion of the business land tax base. ${ }^{36}$ In addition, since capital generates no congestion, the optimal capital tax is zero as (4.11) shows. This confirms that atomistic jurisdictions using multiple tax instrument sets have no incentives to tax capital (Bucovetsky and Wilson, 1991). Note also that since workers involve no congestion, any additional local source-based tax on labor, either on firms or on households, would also be set at zero by the local authorities. ${ }^{37}$ Finally, conditions (4.12) and (4.13) indicate that local public services are provided efficiently. The main findings from this subsection can be summarized in the following proposition:

Proposition 1. Suppose that local governments control $\tau_{i}^{R}, \tau_{i}^{K}, \tau_{i}^{L}, g_{i}$ and $z_{i}$. Then, the decentralized equilibrium is characterized by

(i) a tax on residents that exceeds the marginal congestion cost of residents to internalize their marginal fiscal cost,

(ii) a zero-tax on capital,

(iii) efficient provision of local public goods and factors.

Proposition 1 generalizes the usual first-best results of the WRW model and offers two new insights. ${ }^{38}$ First, in the literature, a complete tax structure requires taxes to internalize the mobility costs of agents and an undistortive tax, usually levied on a fixed production factor. Proposition 1 extends this result to a tax instrument set composed solely of distortive taxes. The explanation for this result is that in the absence of vacant land, a local government can levy taxes on its entire fixed land endowment using separate taxes on residents and business land use. Notice that the household tax plays a dual role - being a part of the undistortive tax but also an instrument to control residents' mobility. The second novel insight is related to the identification of a new marginal cost of household mobility, namely the marginal fiscal cost of residents. This cost which highlights the fact that local authorities face a constant trade-off between hosting firms and hosting households (Lemma 2), provides a new rationale for the heavy reliance on

\footnotetext{
${ }^{36}$ Notice that $\tau_{i}^{R}$ and $\tau_{i}^{L}$ play a symmetric role from the local government's viewpoint. Alternatively $\tau_{i}^{R}$ can be used to clear the budget and $\tau_{i}^{L}$ to internaternalize the net marginal fiscal cost of business land use $\tau_{i}^{R}-R_{i}\left|U_{R}^{i}\right| / U_{x}^{i}$. In this case, the level of $\tau_{i}^{L}$ is defined by (4.10) and the level of $\tau_{i}^{R}$ is obtained by inserting (4.10) into (4.14). This symmetry has important impications when the tax structure is constrained (subsection 4.3).

${ }^{37}$ Allowing workers to cause congestion would not change the results of this paper, provided that a local tax on labor is also introduced to allow local authorities to internalize this additional cost.

${ }^{38}$ The conditions stated in Result 2 are essentially the same as the first-best results discussed in Wilson (1995) (section 3). However, Wilson's results exclude two elements: (1) the marginal fiscal cost $\tau_{i}^{L}$ in (4.10); (2) condition (4.13) since his analysis focuses on local public goods. Result 2 can be seen also as an extension of the optimal behavioral rules in Wellisch and Hulshorst (2000) (section 2).
} 
local household taxes observed in practice, apart from congestion costs which might be quite low and difficult to measure by the local authority.

\subsection{A household tax and a business property tax}

Let us now consider the case where local governments are not allowed to levy separate taxes on capital and land factors. The purpose is to derive the distortions expected from such a constrained tax instrument set, and explain why local governments decide to depart from efficiency. Local governments are assumed to use two different tax instruments only: a head tax on residents $\tau_{i}^{R}$ and a business property tax $\tau_{i}^{P}$ which consists in a unit tax on both capital and land factors. ${ }^{39}$ Local government $i$ is assumed, without loss of generality, to control the tax instrument set $\left\{\tau_{i} ; \tau_{i}^{P}\right\}$, where $\tau_{i} \equiv \tau_{i}^{R}-\tau_{i}^{P}$. Therefore, its budget constraint becomes:

$$
\tau_{i} R_{i}+\tau_{i}^{P}\left(K_{i}+\mathcal{L}_{i}\right)=C\left(g_{i}, z_{i}\right)
$$

It is assumed that while $\tau_{i}, g_{i}$ and $z_{i}$ are chosen freely, $\tau_{i}^{P}$ adjusts to clear (4.15). Using the budget constraint to substitute $\tau_{i}^{P}$ into (4.7) - where $\tau_{i}^{K}$ and $\tau_{i}^{L}$ are replaced by $\tau_{i}^{P}$ - results in (4.8). Thus, the local government's objective does not change, and the optimal choices of $\tau_{i}, g_{i}$ and $z_{i}$ are still characterized by the necessary conditions (4.9). Only the location responses of households and capital differ from the first-best case. Inserting them into the first order conditions, we derive the following result:

Result 3. In equilibrium, under perfect interjurisdictional competition, local governments choose $\tau_{i}^{R}, \tau_{i}^{P}, g_{i}$ and $z_{i}$ in accordance with the following decision rules:

$$
\begin{aligned}
& \tau_{i}^{R}=R_{i} \frac{\left|U_{R}^{i}\right|}{U_{x}^{i}}+\left(1+\frac{K_{i}}{L_{i}}\right) \tau_{i}^{P}, \\
& R_{i} \frac{U_{g}^{i}}{U_{x}^{i}}=C_{g}^{i}, \\
& \frac{F_{z}^{i}-C_{z}^{i}}{K_{i}}=\varepsilon_{i}\left[F_{K z}^{i}-F_{L z}^{i}+\left.\left(F_{K W}^{i}-F_{L W}^{i}\right) \frac{\partial W_{i}}{\partial z_{i}}\right|_{\left(\bar{K}_{i}, \bar{L}_{i}\right)}\right],
\end{aligned}
$$

while satisfying the budget restriction (4.15), so that

$$
\tau_{i}^{P}=\left(1-\kappa_{i}\right) \frac{R_{i}}{\mathcal{L}_{i}}\left(\frac{C^{i}}{R_{i}}-R_{i} \frac{\left|U_{R}^{i}\right|}{U_{x}^{i}}\right),
$$

where $\kappa_{i} \equiv K_{i} /\left(K_{i}+L_{i}\right)$ denotes the capital share in the business property and $\varepsilon_{i}<0$, its elasticity with respect to $\tau_{i}^{P}$; and $\left.\left(\partial W_{i} / \partial z_{i}\right)\right|_{\left(\bar{K}_{i}, \bar{L}_{i}\right)}>0$ is workers' reaction to a public input increase, given $K_{i}$ and $L_{i}$.

Proof. See Appendix D.

\footnotetext{
${ }^{39}$ Wilson (1995) and Braid (1996) investigate a similar combined tax which they refer to as a "business property tax". We retain this terminology in our paper and refer to the sum $K_{i}+L_{i}$ as "business property".
} 
The competitive equilibrium with a combined business property tax is thus characterized by an inefficient allocation - compared to conditions (3.7)-(3.10). To interpret the behavioral rules stated in Result 3, it must be emphasized that, under Assumption 2, condition (4.19) requires the property $\operatorname{tax} \tau_{i}^{P}$ to be positive. That is, jurisdictions are not able to balance their budget without taxing mobile capital, as was possible with two separate business taxes on capital and land. Local governments consequently decide to distort their policy instruments to compensate for this overtaxation of mobile capital. The first of these distortions appears in the choice of the property tax itself. Condition (4.19) shows first that, except in the rare case of a perfectly symmetric equilibrium, property tax levels are intended to differ across jurisdictions, which entails a misallocation of capital in the federation (condition (3.8) is violated). ${ }^{40}$ Interestingly, condition (4.19) offers further information about the causes of this misallocation. It shows that, ceteris paribus, jurisdictions with lower desired business land taxes - as defined by the first-best decision rule (4.14) - and those with more capital-intensive firms are expected to set more attractive tax rates on capital. More generally, condition (4.19) provides a fresh and fairly intuitive characterization of combined business property taxes:

Proposition 2. Suppose that local business taxes on capital and business land use are combined into a single local business property tax. Then:

(i) the property tax level $\tau_{i}^{P}$ is chosen between the first-best desired levels of the two taxes it combines, $\tau_{i}^{K}$ and $\tau_{i}^{L}$, defined respectively by (4.11) and (4.14);

(ii) the higher the capital (land) share in the overall business property of community $i$, the more $\tau_{i}^{P}$ acts as a capital (land) tax.

Proposition 2 indicates that tax competition for mobile capital is fiercer between jurisdictions with highly capital intensive firms, which puts downward pressure on business tax rates. ${ }^{41}$ In other words, the more mobile the tax base of the combined property tax (higher capital share in the business property), the lower its rate.

Comparing condition (4.16) to the first-best decision rule (4.10), indicates that when choosing their household tax levels, local governments treat property taxes and business land taxes in a similar vein. However, the tax on residents now has to internalize an additional marginal fiscal cost $\tau_{i}^{P} K_{i} / L_{i}$. Again, since this distortion need not be the same in every jurisdiction, residents and thus, business land use are misallocated in the federation (condition (3.7) is violated). The intuition behind this suboptimal behavior is straightforward. Consider a small decrease in the household tax allowing community $i$ to attract a new resident. This entry now deprives the jurisdiction of tax revenue for

\footnotetext{
${ }^{40}$ In this framework, a symmetric decentralized equilibrium is all the less likely since jurisdictions potentially have different initial land endowments $\mathcal{L}_{i}$.

${ }^{41}$ To our knowledge, the literature does not provide such a characterization of combined business property taxes. Most studies focus on the distortions caused by a tax structure incorporating a business property tax, without deriving its explicit level.
} 
two reasons. First, the new resident replaces a unit of business land which entails a loss of $\tau_{i}^{P}$, as in the first-best case. Second, due to the complementarity between capital and land $\left(F_{K L}^{i}>0\right)$, this decrease in business land use is accompanied by an outflow of $K_{i} / L_{i}$ units of capital, which also reduces local tax revenues since mobile capital is now taxed at a positive rate. ${ }^{42}$ In other words, by increasing the costs of hosting residents, combined taxation of capital and business land, leads local governments to charge inefficiently high household taxes with respect to business land taxation. This distortion is larger in jurisdictions with highly capital-intensive firms, because they incur higher marginal fiscal costs when new residents crowd out local firms. Here, we are interested in the extent to which local governments actually increase the household tax level. To address this, recall that business property taxes are usually lower than business land taxes, especially in jurisdictions with more capital intensive firms (Proposition 2). This should in part at least, offset the increase in the marginal fiscal cost of residents. Integrating (4.14) and (4.19) respectively into (4.10) and (4.16) reveals that $\tau_{i}^{R}$ is not distorted, which can be summarized in:

Proposition 3. Suppose that local business taxes on capital and business land use are combined into a single local business property tax. Then, despite the increase in the marginal fiscal cost of residents due to the positive taxation of capital, local governments have no incentive to distort local taxes on residents.

Thus, jurisdictions have no incentive to tax mobile residents too heavily, since by lowering their property taxes in order to attract mobile capital, they reduce the increased marginal fiscal cost of mobile residents to its optimal first-best value. Although the introduction of a business property tax distorts the allocation of residents and business land across jurisdictions, the setting of household local taxes is not distorted. That is, local governments distort only the tax instrument that has been constrained. This result contrasts with the analysis in Wilson (1995) which shows that regional authorities balance the distortions between the tax on residents and the property tax. The reason for this difference is that at the sub-metropolitan level, due to the compromise between residents and firms, the tax on residents and the tax on business land play a symmetric role: each of these taxes can be used to internalize the other one, while the other tax allows to clear the local budget. ${ }^{43}$ Thus, in a constrained environment, local authorities have no incentive to distort both instruments and distort only the most appropriate one. ${ }^{44}$ Here, the objective of attracting more capital can be achieved directly by lowering $\tau_{i}^{P}$. Hence, it is not necessary to distort $\tau_{i}^{R}$.

According to condition (4.17) local governments have no incentive to distort the

\footnotetext{
${ }^{42}$ Since, inputs prices ratios are not directly affected by changes in $\tau_{i}^{R}$, homogeneity of $F^{i}$ implies that the relative demand for inputs $K_{i} / L_{i}$ is unchanged.

${ }^{43}$ See footnote 36 .

${ }^{44}$ In the WRW framework, each tax has its own role to play. Therefore, when the tax structure is constrained, each tax is used separately to alleviate directly or indirectly the lack of available instruments, while continuing to play its first-best role partially. See Wellisch (2006).
} 
provision of local public goods, since this would not directly influence capital location, $\partial F_{K}^{i} / \partial g_{i}=0$. The only effect of local public good supply on the marginal productivity of capital is through residents' location responses. Thus, under perfect mobility of households across small jurisdictions, local public goods are provided in accordance with the Samuelson rule. As in the first-best case, decentralized provision of public goods with property taxation provides local governments with the incentives to internalize the preferences of residents.

However, condition (4.18) reveals that local governments distort their supply of local public input. The LHS of (4.18) is the average distortion per capital unit caused by an inefficient supply of local public inputs - compared to the Samuelson rule. The RHS shows the direction of this distortion. The term $F_{K z}^{i}+\left.F_{K W}^{i}\left(\partial W_{i} / \partial z_{i}\right)\right|_{\left(\bar{K}_{i}, \bar{L}_{i}\right)}$ is the overall capital-augmenting impact of the public input - that is, the increase in the marginal product of capital induced by an incremental amount of $z_{i} \cdot{ }^{45}$ Indeed, an additional unit of the public factor increases $F_{K}^{i}$ not just directly, as a technological complement to capital but also indirectly by attracting new workers who improve the productivity of capital as well. Likewise, the other terms in square brackets represent the land-augmenting effect of $z_{i}$. Hence, condition (4.18) states that public inputs are over(under)-provided, i.e. $F_{z}^{i}<(>) C_{z}^{i}$, when the capital-augmenting impact of the public input is stronger (weaker) than its land-augmenting impact. To interpret this result, recall that property taxation involves suboptimally high taxation of mobile capital relative to business land from the jurisdiction's standpoint (Proposition 2). In response, local authorities use public factors to encourage capital location in their jurisdiction whilst not overly stimulating land input demand. By so doing, they increase the capital share in the business property $\kappa_{i}$, which allows them to compensate - at least in part - for the distortive effect of the property tax. ${ }^{46}$ Finally, the elasticity $\varepsilon_{i}$ in (4.18) reveals that the more $\tau_{i}^{P}$ distorts $\kappa_{i}$, the greater the distortion of the local public input. In other words, in jurisdictions where business property taxation involves a stronger distortive effect, local authorities further distort their public input supply to outweigh the first distortion. In summary, we have:

\footnotetext{
${ }^{45}$ The literature on public inputs distinguishes two categories of public factors depending on the technology considered (Hillman 1978; McMillan 1979; Feehan 1989). This paper assumes "factoraugmenting" public inputs (i.e. $F^{i}$ is CRS in private factors only), usually considered as the empirically more relevant case. It implies that public inputs only increase private factors productivity unlike "firmaugmenting" public inputs (i.e. $F^{i}$ is CRS in all factors) which also increase the firms' profit. Comparing the outcomes of these two specifications is beyond the scope of the present analysis. See Matsumoto (1998) for such a comparison when public inputs are financed by a capital tax.

${ }^{46}$ Intuitively, condition (4.18) reads: the local public input is over(under)-provided if and only if it allows jurisdiction $i$ to attract capital(land)-intensive firms.
} 
Proposition 4. Suppose that local business taxes on capital and business land use are combined into a single local business property tax. Then:

(i) local public goods are provided efficiently;

(ii) public inputs are over(under)-provided when the overall capital-augmenting impact of the public input is stronger (weaker) than its overall land-augmenting impact. This distortion increases with the sensitivity of the capital share in the business property to changes in the property tax.

Part (i) of Proposition 4 is similar to the efficiency result derived in Wilson (1995) and Richter and Wellisch (1996): under residents' perfect mobility across atomistic jurisdictions, when the tax instrument set consists of a direct tax on residents and a distortive tax, local governments provide public goods efficiently. ${ }^{47}$ However, a novel finding from this analysis is that due to competition between households and firms on land markets, local authorities also do not distort household taxes when they can also tax business land (Proposition 3). Intuitively, since the direct effect of establishing a business property tax is to distort firms' behavior, local authorities choose to use the instruments that directly affect firms $\left(\tau_{i}^{P}\right.$ and $\left.z_{i}\right)$ to tackle these distortions, while optimally choosing household-oriented instruments $\left(\tau_{i}^{R}\right.$ and $\left.g_{i}\right)$.

Part (ii) of Proposition 4 is in line with Matsumoto and Sugahara (2014). The present study offers several novel insights. First, it reveals the balancing function of local public inputs. The basic reason why local authorities distort their provision of local public factors is to offset the distortions caused by the combined property tax which is too high (low) for a capital (business land) tax (Proposition 2). ${ }^{48}$ Second, we find a distorting impact specific to workers' mobility (or any untaxed mobile factor). To make this intuitively transparent, suppose, for example, a community where both the public input and workers involve a land-augmenting effect which dominates the capitalaugmenting effect: $E_{z}^{i} \equiv F_{K z}^{i}-F_{L z}^{i}<0$, and $E_{W}^{i} \equiv F_{K W}^{i}-F_{L W}^{i}<0$. It follows from (4.18) that the public inuput is under-provided and that higher labor mobility - an increase in $\left.\left(\partial W_{i} / \partial z_{i}\right)\right|_{\left(\bar{K}_{i}, \bar{L}_{i}\right)}$ - exacerbates this under-provision. However, generally $E_{z}^{i}$ and $E_{W}^{i}$ need not have the same sign. Consequently, ignoring the mobility of labor and other untaxed mobile factors might lead not only to overestimating or underestimating the under-provision of $z_{i}$, but might also predict a misleading over-provision. This last point highlights the importance of workers' interjurisdictional mobility and the type of workers attracted by jurisdictions. ${ }^{49}$

\footnotetext{
${ }^{47}$ See also Proposition 4 in Wellisch and Hulshorst (2000).

${ }^{48}$ This result echoes the conclusions in Wellisch and Hulshorst (2000): when their tax instrument set is constrained, regional governments balance the distortions among their available instruments.

${ }^{49}$ These considerations are not accounted for in Matsumoto and Sugahara (2014) since they do not consider an untaxed mobile factor, ie. $\left.\left(\partial W_{i} / \partial z_{i}\right)\right|_{\left(\bar{K}_{i}, \bar{L}_{i}\right)}=0$.
} 


\section{Conclusions}

This paper extends the tax competition model with residents'-workers' mobility developed by Wilson (1995) and Richter and Wellisch (1996), to account for the specific context of sub-metropolitan jurisdictions, such as counties, municipalities, districts or townships. It responds to Brülhart et al. (2015) which highlights the lack of theoretical analysis of tax competition within metropolitan areas in the presence of mobile households. We examined the level of public good and input provision financed by multiple tax instruments, in an economy with residents, workers and capital mobility. Households and firms interact on both the metropolitan labor market and the local land markets, through their demand for local land. We showed that due to competition between households and firms on land markets, sub-metropolitan authorities are obliged to choose continuously between hosting residents and hosting businesses. Two decentralized equilibria have been analyzed. (1) When local governments freely choose a local head tax on residents and two separate local business taxes on capital and land inputs, the efficient allocation is achieved and reveals the existence of a marginal fiscal cost caused by residents' mobility. This cost is a new rationale for heavy reliance on household local taxes observed in practice apart from congestion costs which may actually be quite low and difficult to measure by local authorities. (2) When local authorities are constrained to use a combined business property tax, they charge inefficiently high (low) taxation on capital (land) and use public inputs so as to compensate the distortive effects of the business property tax. Sub-metropolitan governments only distort the firm-oriented instruments - property taxes and local public inputs - while optimally choosing the household-oriented instruments - taxes on residents and local public goods.

Our analysis suggests that gains could be obtained of engaging local tax limitation reforms that would involve a removal of capital from the property tax base in countries where municipalities and other sub-metropolitan jurisdictions are constrained to make use of combined business property taxes. Such reforms have been implemented in several states of the United States (Illinois, 1979; Ohio, 2005; Michigan, 2014). ${ }^{50}$ The Taxe professionnelle reform (France, 2010) also consisted of such a tax limitation. Empirical evaluations of the outcomes of this type of reform on tax setting and public services provision could shed an interesting light on tax competition at the sub-metropolitan level.

Much remains to be done to develop our understanding of sub-metropolitan governments' behavior when facing a high degree of interjurisdictional mobility of both households and firms. One weakness of our analysis is that, in modeling interactions between jurisdictions, we have assumed perfect atomicity of communities. However, it is typically the case that municipalities have some degree of market power due to attachment of residents to home (Mansoorian and Myers, 1993) and commuting costs

\footnotetext{
${ }^{50}$ See Stafford and DeBoer (2014) for a detailed discussion of such reforms in the United States.
} 
(Braid, 2000). To our knowledge, there exists no theoretical investigation of such a two-dimensional household imperfect mobility. This might however provide a more accurate picture of how residential and labor mobility respectively affect local policies. Especially, it could give further insights on how household imperfect mobility affect the local trade-off between hosting households or firms and the extent to which local public goods provision remains efficient in a second-best environment. Another weakness is that in line with most of the existing literature, our analysis ignores dynamic aspects. In reality, decisions made by local governments account for capital accumulation, and local public debt constitutes an important part of municipal budgets. Accordingly, local public policies are likely to be more subtle than our analysis suggests. A few recent studies have started to introduce dynamic issues in the traditional tax competition model (Wildasin 2003, 2011) or in frameworks with imperfect household mobility (Han et al., 2013). ${ }^{51}$ Integrating these two types of mobility could be a promising direction for future research.

\section{Appendix A}

The basic purpose of this appendix is to prove Result $1 .{ }^{52}$ To this end, we assume that the economy is characterized by the resource constraints (2.1)-(2.3) and that the agents behave according to (2.4)-(2.11). Let us prove that a necessary and sufficient condition for implementing the efficient allocation - defined by the constraints (2.1)-(2.4) and (3.1), and the optimal conditions (3.2)-(3.6) - is that the instruments $\left\{\tau_{i}^{R}, \tau_{i}^{K}, \tau_{i}^{L}, g_{i}, z_{i}\right\}$ satisfy conditions (3.7)-(3.10). ${ }^{53}$

First, observe that in a decentralized economy households migrate at no cost and all markets are clearing. Hence, the constraints (2.1)-(2.4) are satisfied. Besides, from the resident's budget constraint (2.6) and the zero-profit condition (2.10), it follows that

$$
\begin{aligned}
\sum_{i=1}^{n}\left[F^{i}-R_{i} x_{i}-C^{i}\right]=\sum_{i=1}^{n}\left[w W_{i}+\left(r+\tau_{i}^{K}\right) K_{i}+\left(\rho_{i}+\tau_{i}^{L}\right) L_{i}\right. & \\
- & \left.-R_{i}\left(y-\rho_{i}-\tau_{i}^{R}\right)-C^{i}\right]=0
\end{aligned}
$$

where the last equality is obtained using the definition of the individual income (2.5) and the local government budget constraint (2.11). Therefore, the feasibility constraint of the economy (3.1) is satisfied. Also, noting that the wage rate $w$ is the same in the whole federation, it follows from (2.7) that condition (3.4) is ensured in equilibrium.

Let us now turn to the tax system. Inserting (2.6) for $x_{i}$ and (2.9) for $\rho_{i}$ into both sides of the condition for efficient allocation of residents (3.2) yields condition (3.7).

\footnotetext{
${ }^{51}$ See Keen and Konrad (2014) for a review of tax competition models with dynamic aspects.

${ }^{52}$ The proof follows the methological approach in Wellisch (2006) (Chapter 2).

${ }^{53}$ Note that, conditions (2.4), (3.2), (3.3) and (3.4) constitute $4 \times(n-1)$ equations. Thus, if the problem is well-behaved, the $7 n$ variables $x_{i}, g_{i}, z_{i}, R_{i}, W_{i}, K_{i}$ and $L_{i}$ are uniquely determined by the $7 n$ conditions (2.1)-(2.4) and (3.1)-(3.6).
} 
This proves that conditions (3.2) and (3.7) are equivalent when allowing for private behaviors. And, inserting (2.8) for $F_{K}^{i}$ into (3.3) proves that the condition for efficient capital allocation (3.3) and (3.8) are equivalent.

Finally, noting that the public services provision rules (3.5) and (3.6) are respectively identical to (3.9) and (3.10) allows us to complete the proof.

\section{Appendix B}

\section{B.1 Necessary conditions}

This paragraph derives the first-order conditions of the local government (4.9). Differentiating the local government's objective (4.8) with respect to $t \in\left\{\tau ; \tau^{K} ; g ; z\right\}$ and the conditions for the optimal inputs demand (2.7)-(2.9), it follows that

$$
\frac{d \Omega}{d t}=\tau R_{t}+\tau^{K} K_{t}-C_{g} g_{t}+\left(F_{z}-C_{z}\right) z_{t}+R\left(F_{L t}+\tau_{t}\right)=0
$$

where subscripts stand for derivatives. ${ }^{54}$ Besides, differentiating the migration equilibrium (4.5), we have

$$
F_{L t}+\tau_{t}=\frac{U_{R}}{U_{x}} R_{t}+\frac{U_{g}}{U_{x}} g_{t}
$$

Inserting (A.2) into (A.1), the first-order conditions (4.9) result.

\section{B.2 Location responses}

We now derive the location responses of residents, workers and capital to local policy changes. First, note that since $F$ exhibits constant returns to scale in the private factors, Euler's theorem requires that $F=W F_{W}+K F_{K}+L F_{L}$. Differentiating this condition with respect to $W, K, L$ and $z$ yields

$$
\begin{aligned}
& W F_{W W}+K F_{W K}+L F_{W L}=0 \\
& W F_{K W}+K F_{K K}+L F_{K L}=0 \\
& W F_{L W}+K F_{L K}+L F_{L L}=0 \\
& W F_{z W}+K F_{z K}+L F_{z L}=F_{z}
\end{aligned}
$$

Differentiating the equilibrium conditions (4.3)-(4.5) with respect to $t \in\left\{\tau, \tau^{K}, g, z\right\}$, it follows that

$$
\left(\begin{array}{lll}
F_{W W} & -F_{W L} & F_{W K} \\
F_{K W} & -F_{K L} & F_{K K} \\
F_{L W} & -F_{L L}-\frac{U_{R}}{U_{x}} & F_{L K}
\end{array}\right)\left(\begin{array}{c}
W_{t} \\
R_{t} \\
K_{t}
\end{array}\right)=\left(\begin{array}{r}
-F_{W z} z_{t} \\
\tau_{t}^{K}-F_{K z} z_{t} \\
-\tau_{t}+\frac{U_{g}}{U_{x}} g_{t}-F_{L z} z_{t}
\end{array}\right)
$$

\footnotetext{
${ }^{54}$ In the following appendices, the jurisdiction index $i$ is dropped for notational convenience.
} 
Let $A$ denote the first matrix on the LHS of (A.7). ${ }^{55}$ Performing the row operation

$$
r_{3} \leftarrow W r_{1}+K r_{2}+L r_{3}
$$

on the third row of $|A|$, and using (A.3)-(A.5) yields

$$
|A|=\frac{U_{R}}{U_{x}} D
$$

where $D=\left|\begin{array}{cc}F_{W W} & F_{W K} \\ F_{K W} & F_{K K}\end{array}\right| \cdot{ }^{56}$ It will prove useful in the sequel to notice that

$$
D=-\frac{L}{W}\left|\begin{array}{cc}
F_{W L} & F_{W K} \\
F_{K L} & F_{K K}
\end{array}\right|=-\frac{L}{K}\left|\begin{array}{cc}
F_{W W} & F_{W L} \\
F_{K W} & F_{K L}
\end{array}\right|>0
$$

The first (second) equality of (A.9) is obtained applying the column operation $c_{1}\left(c_{2}\right) \leftarrow$ $\frac{W}{L} c_{1}+\frac{K}{L} c_{2}$ to the first (second) column of $D .{ }^{57}$

Let us now derive the migration responses of residents. Applying Cramer's rule to (A.7), it comes

$$
R_{t}=\frac{U_{x}}{U_{R} D}\left|\begin{array}{rrr}
F_{W W} & -F_{W z} z_{t} & F_{W K} \\
F_{K W} & \tau_{t}^{K}-F_{K z} z_{t} & F_{K K} \\
F_{L W} & -\tau_{t}+\frac{U_{g}}{U_{x}} g_{t}-F_{L z} z_{t} & F_{L K}
\end{array}\right|
$$

Using the row operation (A.8) and equalities (A.3),(A.4) and (A.6), we obtain

$$
R_{t}=G_{t} \frac{U_{x}}{U_{R}}
$$

where $G_{t} \equiv \tau_{t}-\frac{K}{L} \tau_{t}^{K}-\frac{U_{g}}{U_{x}} g_{t}+\frac{F_{z}}{L} z_{t}$. It follows that

$$
R_{\tau}=\frac{U_{x}}{U_{R}}, \quad R_{\tau^{K}}=-\frac{K}{L} \frac{U_{x}}{U_{R}}, \quad R_{g}=-\frac{U_{g}}{U_{R}}, \quad R_{z}=\frac{U_{x}}{U_{R}} \frac{F_{z}}{L} .
$$

which proves the signs of the responses $R_{t}, t \in\left\{\tau ; \tau^{K} ; g ; z\right\}$ in Lemma $2 .{ }^{58}$

Identically,

$$
W_{t}=\frac{U_{x}}{U_{R} D}\left[G_{t}\left|\begin{array}{cc}
F_{W L} & F_{W K} \\
F_{K L} & F_{K K}
\end{array}\right|+\frac{U_{R}}{U_{x}}\left|\begin{array}{rr}
-F_{W z} z_{t} & F_{W K} \\
\tau_{t}^{K}-F_{K z} z_{t} & F_{K K}
\end{array}\right|\right]
$$

\footnotetext{
${ }^{55}$ Notice that from Schwarz's theorem, $\forall X, Y \in\{W ; K ; L\}, F_{X Y}=F_{Y X}$.

${ }^{56}$ To solve (A.7) for $W_{t}, R_{t}$ and $K_{t}$, the determinant $|A|$ must be nonzero which is the case since $U_{R}<0$ due to congestion, and $D>0$ (see below).

${ }^{57}$ The derivations make extensive use of the following calculation rule for determinants: $\left|c_{1} \ldots c_{j} \ldots c_{p}\right|=\frac{1}{\alpha_{j}}\left|c_{1} \ldots \sum_{\substack{k=1 \\(\text { column } j)}}^{p} \alpha_{k} c_{k} \ldots c_{p}\right|$, where $c_{j}$ is the $j^{\text {th }}$ column vector. Since $\left|{ }^{t} A\right|=|A|$, the same rule applies to row operations.

${ }^{58}$ To establish the signs of the location responses, recall that: $U_{x}>0, U_{g}>0, U_{R}<0, F_{X}>0$, $F_{X X}<0$ and $F_{X Y}>0$ for all $X$ and $Y$ in $\{W ; K ; L ; z\}$.
} 
Inserting (A.9) into (A.12) yields

$$
W_{t}=-G_{t} \frac{W}{L} \frac{U_{x}}{U_{R}}+\frac{1}{D}\left|\begin{array}{rr}
-F_{W z} z_{t} & F_{W K} \\
\tau_{t}^{K}-F_{K z} z_{t} & F_{K K}
\end{array}\right|
$$

The location responses of workers are thus given by

$$
\begin{aligned}
& W_{\tau}=-\frac{W}{L} \frac{U_{x}}{U_{R}}, \quad W_{\tau^{K}}=\frac{K W}{L^{2}} \frac{U_{x}}{U_{R}}-\frac{F_{W K}}{D}, \\
& W_{g}=\frac{W}{L} \frac{U_{g}}{U_{R}}, \quad W_{z}=-\frac{W}{L^{2}} F_{z} \frac{U_{x}}{U_{R}}+\frac{F_{W K} F_{K z}-F_{K K} F_{W z}}{D} .
\end{aligned}
$$

which proves the signs of the responses $W_{t}, t \in\left\{\tau ; \tau^{K} ; g ; z\right\}$ in Lemma 2. Notice that the signs of the responses (A.13) are unambiguous, since $D>0$ from (A.9).

Finally, the same calculations give

$$
K_{t}=-G_{t} \frac{K}{L} \frac{U_{x}}{U_{R}}+\frac{1}{D}\left|\begin{array}{rr}
F_{W W} & -F_{W z} z_{t} \\
F_{K W} & \tau_{t}^{K}-F_{K z} z_{t}
\end{array}\right|
$$

so that,

$$
\begin{aligned}
& K_{\tau}=-\frac{K}{L} \frac{U_{x}}{U_{R}}, \quad K_{\tau^{K}}=\left(\frac{K}{L}\right)^{2} \frac{U_{x}}{U_{R}}+\frac{F_{W W}}{D} \\
& K_{g}=\frac{K}{L} \frac{U_{g}}{U_{R}}, \quad K_{z}=-\frac{K}{L^{2}} F_{z} \frac{U_{x}}{U_{R}}+\frac{F_{K W} F_{W z}-F_{W W} F_{K z}}{D} .
\end{aligned}
$$

which proves the signs of the responses $K_{t}, t \in\left\{\tau ; \tau^{K} ; g ; z\right\}$ in Lemma 2.

\section{Appendix $\mathrm{C}$}

The basic purpose of this appendix is to prove Result 2. From the first order condition (4.9),

$$
\begin{aligned}
& \left(\tau+R \frac{U_{R}}{U_{x}}\right) R_{\tau}+\tau^{K} K_{\tau}=0 \\
& \left(\tau+R \frac{U_{R}}{U_{x}}\right) R_{\tau^{K}}+\tau^{K} K_{\tau^{K}}=0 \\
& \left(\tau+R \frac{U_{R}}{U_{x}}\right) R_{g}+\tau^{K} K_{g}+R \frac{U_{g}}{U_{x}}-C_{g}=0 \\
& \left(\tau+R \frac{U_{R}}{U_{x}}\right) R_{z}+\tau^{K} K_{z}+F_{z}-C_{z}=0
\end{aligned}
$$

Yet, using (A.11) and (A.14) yields

$$
\left|\begin{array}{cc}
R_{\tau} & K_{\tau} \\
R_{\tau^{K}} & K_{\tau^{K}}
\end{array}\right|=\frac{U_{x}}{U_{R}} \frac{F_{W W}}{D} \neq 0
$$

Then, equations (A.1) and (A.2) imply

$$
\begin{aligned}
& \tau+R \frac{U_{R}}{U_{x}}=0 \\
& \tau^{K}=0
\end{aligned}
$$


which proves the optimal taxation rules (4.10) and (4.11), recalling that $\tau=\tau^{R}-\tau^{L}$. Inserting (A.5) and (A.6) into (A.3) and (A.4), the Samuelson rules (4.12) and (4.13) follow.

Finally, using (A.5) and (A.6) to substitute $\tau$ and $\tau^{K}$ into the local budget constraint (4.6) yields the optimal condition for $\tau^{L}(4.14)$.

\section{Appendix D}

\section{D.1 Locational system}

The basic purpose of this appendix is to prove Result 3. Using (4.15) to substitute for $\tau^{P}$ into (4.4), the locational system becomes

$$
\begin{aligned}
& F_{W}(W, K, \mathcal{L}-R, z)-w=0 \\
& F_{K}(W, K, \mathcal{L}-R, z)+\frac{\tau R-C}{K+\mathcal{L}}-r=0 \\
& U\left[\bar{y}-F_{L}(W, K, \mathcal{L}-R, z)-\tau, g, R\right]-\bar{u}=0
\end{aligned}
$$

Differentiating (A.1)-(A.3) with respect to $t \in\{\tau, g, z\}$, it follows that

$$
\begin{aligned}
\left(\begin{array}{lll}
F_{W W} & -F_{W L} & F_{W K} \\
F_{K W} & -F_{K L}+\frac{\tau}{K+\mathcal{L}} & F_{K K}+\frac{\tau^{P}}{K+\mathcal{L}} \\
F_{L W} & -F_{L L}-\frac{U_{R}}{U_{x}} & F_{L K}
\end{array}\right)\left(\begin{array}{c}
W_{t} \\
R_{t} \\
K_{t}
\end{array}\right) \\
\quad=\left(\begin{array}{r}
-F_{W z} z_{t} \\
-\frac{R}{K+\mathcal{L}} \tau_{t}+\frac{C_{g}}{K+\mathcal{L}} g_{t}+\left(\frac{C_{z}}{K+\mathcal{L}}-F_{K z}\right) z_{t} \\
-\tau_{t}+\frac{U_{g}}{U_{x}} g_{t}-F_{L z} z_{t}
\end{array}\right)
\end{aligned}
$$

Let $B$ denote the first matrix on the LHS of (A.4).

\section{D.2 Household taxation rules}

Let us start with the choice of $\tau$ whose second-best value is determined by the necessary condition (4.9), where $\tau^{P}$ replaces $\tau^{K}$ :

$$
\left(\tau+R \frac{U_{R}}{U_{x}}\right) R_{\tau}+\tau^{P} K_{\tau}=0
$$

As in the first-best case, Cramer's rule is used to solve for $R_{\tau}$ and $K_{\tau}$ from (A.4). Inserting these expressions into (A.5), the first-order condition becomes 


$$
\begin{aligned}
& \left(\tau+R \frac{U_{R}}{U_{x}}\right)\left|\begin{array}{lcl}
F_{W W} & 0 & F_{W K} \\
F_{K W} & -\frac{R}{K+\mathcal{L}} & F_{K K}+\frac{\tau^{P}}{K+\mathcal{L}} \\
F_{L W} & -1 & F_{L K}
\end{array}\right| \\
& +\tau^{P}\left|\begin{array}{llc}
F_{W W} & -F_{W L} & 0 \\
F_{K W} & -F_{K L}+\frac{1}{K+\mathcal{L}}\left(\tau+R \frac{U_{R}}{U_{x}}\right)-\frac{R}{K+\mathcal{L}} \frac{U_{R}}{U_{x}} & -\frac{R}{K+\mathcal{L}} \\
F_{L W} & -F_{L L}-\frac{U_{R}}{U_{x}} & -1
\end{array}\right|=0
\end{aligned}
$$

Noting that the terms $\frac{\tau^{P}}{K+\mathcal{L}}$ and $\frac{1}{K+\mathcal{L}}\left(\tau+R \frac{U_{R}}{U_{x}}\right)$ cancel each other and applying the row operation (A.8) to both determinants, it follows that

$$
\begin{aligned}
\left(\tau+R \frac{U_{R}}{U_{x}}\right)\left|\begin{array}{ccc}
F_{W W} & 0 & F_{W K} \\
F_{K W} & -\frac{R}{K+\mathcal{L}} & F_{K K} \\
0 & \alpha & 0
\end{array}\right| & +\tau^{P}\left|\begin{array}{ccc}
F_{W W} & -F_{W L} & 0 \\
F_{K W} & -F_{K L}-\frac{R}{K+\mathcal{L}} \frac{U_{R}}{U_{x}} & -\frac{R}{K+\mathcal{L}} \\
0 & \alpha \frac{U_{R}}{U_{x}} & \alpha
\end{array}\right|=0
\end{aligned}
$$

where $\alpha=\frac{K R}{K+\mathcal{L}}+L$. Operating $r_{2} \leftarrow r_{2}+\frac{1}{\alpha} \frac{R}{K+\mathcal{L}} r_{3}$ on the right determinant, and developing the resulting determinants yields

$$
\left(\tau+R \frac{U_{R}}{U_{x}}\right) D+\tau^{P}\left|\begin{array}{ll}
F_{W W} & F_{W L} \\
F_{K W} & F_{K L}
\end{array}\right|=0
$$

Dividing (A.6) by $D$ and using (A.9), it comes

$$
\tau+R \frac{U_{R}}{U_{x}}-\frac{K}{L} \tau^{P}=0
$$

which proves the second-best taxation rule (4.16).

Finally, using (A.7) to substitute $\tau$ into the local budget constraint (4.15) yields the optimal condition for $\tau^{P}(4.19)$.

\section{D.3 Public good provision rule}

Consider now the choice of $g$. Replacing $\tau^{R}+\frac{U_{R}}{U_{x}}$ from the second-best taxation rule (A.7) into (4.9), it follows that

$$
\tau^{P}\left(\frac{K}{L} R_{g}+K_{g}\right)+R \frac{U_{g}}{U_{x}}-C_{g}=0
$$


Using again Cramer's rule and inverting the last two columns in the expression of $R_{g}$, it comes

$$
\begin{gathered}
R_{g}=-|B|^{-1}\left|\begin{array}{lll}
F_{W W} & F_{W K} & 0 \\
F_{K W} & F_{K K}+\frac{\tau^{P}}{K+\mathcal{L}} & \frac{C_{g}}{K+\mathcal{L}} \\
F_{L W} & F_{L K} & \frac{U_{g}}{U_{x}}
\end{array}\right|, \\
K_{g}=-|B|^{-1}\left|\begin{array}{lll}
F_{W W} & F_{W L} & 0 \\
F_{K W} & F_{K L}-\frac{\tau}{K+\mathcal{L}} & \frac{C_{g}}{K+\mathcal{L}} \\
F_{L W} & F_{L L}+\frac{U_{R}}{U_{x}} & \frac{U_{g}}{U_{x}}
\end{array}\right|
\end{gathered}
$$

and operating $c_{2} \leftarrow-c_{2}+\frac{K}{L} c_{3}$ on the second column of $|B|$, we obtain

$$
|B|=-\left|\begin{array}{lll}
F_{W W} & \gamma^{W} & F_{W K} \\
F_{K W} & \gamma^{K}-\frac{1}{K+\mathcal{L}}\left(\tau-\frac{K}{L} \tau^{P}\right) & F_{K K}+\frac{\tau^{P}}{K+\mathcal{L}} \\
F_{L W} & \gamma^{L}+\frac{U_{R}}{U_{x}} & F_{L K}
\end{array}\right|
$$

where $\gamma^{W} \equiv \frac{K}{L} F_{W K}+F_{W L}, \gamma^{K} \equiv \frac{K}{L} F_{K K}+F_{K L}$ and $\gamma^{L} \equiv \frac{K}{L} F_{L K}+F_{L L}$. Multiplying (A.8) by $-|B|$, introducing the explicit forms of $R_{g}, K_{g}$ and $|B|$, and adding determinants yields

$$
\left|\begin{array}{lll}
F_{W W} & \gamma^{W} & \Gamma F_{W K} \\
F_{K W} & \gamma^{K}-\frac{1}{K+\mathcal{L}}\left(\tau-\frac{K}{L} \tau^{P}\right) & \Gamma\left(F_{K K}+\frac{\tau^{P}}{K+\mathcal{L}}\right)+\tau^{P} \frac{C_{g}}{K+\mathcal{L}} \\
F_{L W} & \gamma^{L}+\frac{U_{R}}{U_{x}} & \Gamma F_{L K}+\tau^{P} \frac{U_{g}}{U_{x}}
\end{array}\right|=0
$$

where $\Gamma \equiv R \frac{U_{g}}{U_{x}}-C_{g}$ has been introduced for convenience. Operating $c_{2} \leftarrow c_{2}+\frac{W}{L} c_{1}$, using Euler's expressions (A.3)-(A.5) and condition (A.7) to simplify terms, it follows that

$$
\left|\begin{array}{lll}
F_{W W} & 0 & \Gamma F_{W K} \\
F_{K W} & \frac{R}{K+\mathcal{L}} \frac{U_{R}}{U_{x}} & \Gamma F_{K K}+\frac{\tau^{P}}{K+\mathcal{L}} R_{\frac{U_{g}}{U_{x}}} \\
F_{L W} & \frac{U_{R}}{U_{x}} & \Gamma F_{L K}+\tau^{P} \frac{U_{g}}{U_{x}}
\end{array}\right|=0
$$

Performing $r_{2} \leftarrow W r_{1}+(K+\mathcal{L}) r_{2}-R r_{3}$, simplifying from (A.3)-(A.5) and collecting terms, we obtain

$$
\left(R \frac{U_{g}}{U_{x}}-C_{g}\right)\left|\begin{array}{ll}
F_{W W} & F_{W K} \\
F_{K W}-F_{L W} & F_{K K}-F_{L K}
\end{array}\right|=0
$$

It is straightforward to derive from (A.9) that the determinant in (A.9) equals $\frac{K+L}{L} D \neq$ 0 . This proves the Samuelson rule (4.17).

\section{D.4 Public input provision rule}

Finally, let us prove the second-best public choice rule for $z$. This proof follows rigorously the same computation steps as in the derivation of the second-best public good provision 
rule. Therefore, we provide only the main steps of the proof. As, above, we start with replacing $\tau^{R}+\frac{U_{R}}{U_{x}}$ from (A.7) into (4.9), which yields

$$
\tau^{P}\left(\frac{K}{L} R_{z}+K_{z}\right)+F_{z}-C_{z}=0
$$

Then, applying Cramer's rule to get explicit forms for $R_{z}$ and $K_{z}$, integrating them into (A.10) and operating $c_{2} \leftarrow c_{2}+\frac{W}{L} c_{1}$, it follows that

$$
\left|\begin{array}{lll}
F_{W W} & 0 & \Lambda F_{W K}-\tau^{P} F_{W z} \\
F_{K W} & \frac{R}{K+\mathcal{L}} \frac{U_{R}}{U_{x}} & \Lambda F_{K K}+\tau^{P}\left(\frac{F_{z}}{K+\mathcal{L}}-F_{K z}\right) \\
F_{L W} & \frac{U_{R}}{U_{x}} & \Lambda F_{L K}+\tau^{P} F_{L z}
\end{array}\right|=0
$$

where $\Lambda \equiv F_{z}-C_{z}$. Performing $r_{2} \leftarrow W r_{1}+(K+\mathcal{L}) r_{2}+R r_{3}$, simplifying terms using (A.3)-(A.6) and collecting terms, we obtain

$$
\left(F_{z}-C_{z}\right)\left|\begin{array}{ll}
F_{W W} & F_{W K} \\
F_{K W}-F_{L W} & F_{K K}-F_{L K}
\end{array}\right|
$$

$$
-\tau^{P}\left|\begin{array}{ll}
F_{W W} & F_{W z} \\
F_{K W}-F_{L W} & F_{K z}-F_{L z}
\end{array}\right|=0
$$

Since the first determinant in (A.9) equals $\frac{K+L}{L} D \neq 0$ from (A.9). Straightforward manipulations yield

$$
F_{z}-C_{z}=\tau^{P} \frac{L}{K+L} \frac{F_{W W}}{D}\left[F_{K z}-F_{L z}-\frac{F_{W z}}{F_{W W}}\left(F_{K W}-F_{L W}\right)\right]
$$

Notice that differentiating (A.1), given the equilibrium values $\bar{K}$ and $\bar{L}$, yields

$$
\left.\frac{\partial W}{\partial z}\right|_{(\bar{K}, \bar{L})}=-\frac{F_{W z}}{F_{W W}}>0
$$

Besides, the elasticity of the capital share in the overall business property with respect to property tax changes writes

$$
\varepsilon=\tau^{P} \frac{K+L}{K}\left(\frac{K}{K+L}\right)_{\tau^{P}}=\tau^{P} \frac{L}{K+L} \frac{1}{K}\left(K_{\tau^{P}}+\frac{K}{L} R_{\tau^{P}}\right)
$$

where the second equality is obtained by recalling that $L_{\tau^{P}}=-R_{\tau^{P}}$ from the land market clearing condition (2.3). And, replacing $\tau^{K}$ by $\tau^{P}$ and $\tau$ by $\tau^{R}-\tau^{P}$ into the locational system (4.3)-(4.5) allows to derive by differentiation,

$$
R_{\tau^{P}}=-\frac{K+L}{L} \frac{U_{x}}{U_{R}} \quad \text { and } \quad K_{\tau^{P}}=\frac{F_{W W}}{D}+\frac{K(K+L)}{L^{2}} \frac{U_{x}}{U_{R}}
$$

Integrating these expressions into (A.13) yields

$$
\varepsilon=\tau^{P} \frac{L}{K+L} \frac{F_{W W}}{D}<0
$$

Finally, inserting (A.12) and (A.14) into (A.11), the optimal second-best condition (4.18) follows. 


\section{References}

Baskaran, T. (2014). Identifying local tax mimicking with administrative borders and a policy reform. Journal of Public Economics 118, 41-51.

Bergstrom, T. C. and R. P. Goodman (1973). Private demands for public goods. The American Economic Review 63(3), 280-296.

Boadway, R. (1980). A note on the market provision of club goods. Journal of Public Economics 13(1), 131-137.

Borcherding, T. E. and R. T. Deacon (1972). The demand for the services of non-federal governments. The American economic review 62(5), 891-901.

Braid, R. M. (1996). Symmetric Tax Competition with Multiple Jurisdictions in Each Metropolitan Area. American Economic Review 86(5), 1279-90.

Braid, R. M. (2000). A spatial model of tax competition with multiple tax instruments. Journal of Urban Economics 47(1), 88 - 114.

Brülhart, M., S. Bucovetsky, and K. Schmidheiny (2015). Chapter 17 - taxes in cities. In J. V. H. Gilles Duranton and W. C. Strange (Eds.), Handbook of Regional and Urban Economics, Volume 5 of Handbook of Regional and Urban Economics, pp. 1123 - 1196. Elsevier.

Brueckner, J. K. (2000). A Tiebout/tax-competition model. Journal of Public Economics $77(2), 285-306$.

Bucovetsky, S. (1995). Rent seeking and tax competition. Journal of Public Economics 58(3), $337-363$.

Bucovetsky, S. (2011). Incentive equivalence with fixed migration costs. Journal of Public Economics 95(11), 1292-1301.

Bucovetsky, S. and J. D. Wilson (1991). Tax competition with two tax instruments. Regional Science and Urban Economics 21 (3), 333-350.

Burbidge, J. B. and G. M. Myers (1994). Population mobility and capital tax competition. Regional Science and Urban Economics 24(4), 441-459.

Edwards, J. H. (1990). Congestion function specification and the "publicness" of local public goods. Journal of Urban Economics 27(1), 80-96.

Epple, D. and A. Zelenitz (1981). The Implications of Competition among Jurisdictions: Does Tiebout Need Politics? Journal of Political Economy 89(6), 1197-1217.

Feehan, J. P. (1989). Pareto-Efficiency with Three Varieties of Public Input. Public Finance $=$ Finances publiques 44(2), 237-48. 
Fisher, R. C. (2015). State and local public finance, chicago: Richard d. irwin.

Gaigné, C., S. Riou, and J.-F. Thisse (2015). How to make the metropolitan area work? neither big government, nor laissez-faire. Journal of Public Economics.

Han, Y., P. Pieretti, and B. Zou (2013). An extension of the home-attachment criteria under dynamic tax competition. Economics Letters 121(3), 508-510.

Henderson, J. V. (1985). The Tiebout Model: Bring Back the Entrepreneurs. Journal of Political Economy 93(2), 248-64.

Hettich, W. and S. L. Winer (1988). Economic and political foundations of tax structure. The American Economic Review, 701-712.

Hettich, W. and S. L. Winer (1999). Democratic choice and taxation: A theoretical and empirical investigation.

Hillman, A. L. (1978). Symmetries and asymmetries between public input and public good equilibria. Public Finance= Finances publiques 33(3), 269-79.

Hoyt, W. H. (1991). Competitive jurisdictions, congestion, and the Henry George Theorem : When should property be taxed instead of land? Regional Science and Urban Economics 21(3), 351-370.

Isen, A. (2014). Do local government fiscal spillovers exist? evidence from counties, municipalities, and school districts. Journal of Public Economics 110, 57-73.

Janeba, E. and S. Osterloh (2013). Tax and the city — a theory of local tax competition. Journal of Public Economics 106(0), 89-100.

Keen, M. and K. A. Konrad (2014). The theory of international tax competition and coordination.

Krelove, R. (1993). The persistence and inefficiency of property tax finance of local public expenditures. Journal of Public Economics 51(3), 415-435.

Lincoln Institute of Land Policy (2014). Significant Features of the Property Tax. http://www.lincolninst.edu/subcenters/significant-features-property-tax/ Report_Property_Tax_Classification.aspx. Accessed March 2016.

Lyytikäinen, T. (2012). Tax competition among local governments: Evidence from a property tax reform in finland. Journal of Public Economics 96(7), 584-595.

Mansoorian, A. and G. M. Myers (1993). Attachment to home and efficient purchases of population in a fiscal externality economy. Journal of Public Economics 52(1), $117-132$.

Matsumoto, M. (1998). A note on tax competition and public input provision. Regional Science and Urban Economics 28(4), 465-473. 
Matsumoto, M. and K. Sugahara (2014). Factor taxation and public-input provision under tax competition: A note. Technical report, Discussion Paper Series.

McKenzie, B. (2013). County-to-county commuting flows: 2006-10. US Census Bureau.

McLure, C. E. (1986). Tax competition: Is what's good for the private goose also good for the public gander? National Tax Journal 39(3), 341-348.

McMillan, J. (1979). A note on the economics of public intermediate goods. Public Finance $=$ Finances publiques 34(2), 293-99.

McMillan, M. L., W. R. Wilson, and L. M. Arthur (1981). The publicness of local public goods: Evidence from ontario municipalities. Canadian Journal of Economics, 596-608.

Mieszkowski, P. and G. R. Zodrow (1989). Taxation and the Tiebout Model: The Differential Effects of Head Taxes, Taxes on Land Rents, and Property Taxes. Journal of Economic Literature 27(3), 1098-1146.

Myers, G. M. and Y. Y. Papageorgiou (1993). Fiscal inequivalence, incentive equivalence and pareto efficiency in a decentralized urban context. Journal of Urban Economics 33(1), $29-47$.

Oates, W. E. et al. (1972). Fiscal federalism. Books.

Richter, W. F. and D. Wellisch (1996). The provision of local public goods and factors in the presence of firm and household mobility. Journal of Public Economics 60(1), 73-93.

Stafford, J. and L. DeBoer (2014). The personal poroperty tax in indiana: Its reduction or elimination is no simple task. Indiana Fiscal Policy Institute.

Tiebout, C. M. (1956). A Pure Theory of Local Expenditures. Journal of Political Economy 64, 416.

Wellisch, D. (1994). Interregional spillovers in the presence of perfect and imperfect household mobility. Journal of Public Economics 55(2), 167-184.

Wellisch, D. (2006). Theory of Public Finance in a Federal State. Number 9780521026871 in Cambridge Books. Cambridge University Press.

Wellisch, D. and J. Hulshorst (2000). A Second-Best Theory of Local Government Policy. International Tax and Public Finance 7(1), 5-22.

Wildasin, D. (2013). Urban public finance. Routledge.

Wildasin, D. E. (2003). Fiscal competition in space and time. Journal of Public Economics 87(11), 2571-2588. 
Wildasin, D. E. (2011). Fiscal competition for imperfectly-mobile labor and capital: A comparative dynamic analysis. Journal of Public Economics 95(11), 1312-1321.

Wilson, J. D. (1984). The excise tax effects of the property tax. Journal of Public Economics 24(3), 309-329.

Wilson, J. D. (1986). A theory of interregional tax competition. Journal of Urban Economics 19(3), 296-315.

Wilson, J. D. (1995). Mobile Labor, Multiple Tax Instruments, and Tax Competition. Journal of Urban Economics 38(3), 333-356.

Wilson, J. D. (1997). Property taxation, congestion, and local public goods. Journal of Public Economics 64(2), 207-217.

Wilson, J. D. (2003). Wilson, John D.: The property tax: Competing views and a hybrid theory - Comments. Chapters in Economics. University of Munich, Department of Economics.

Zodrow, G. R. and P. Mieszkowski (1986). Pigou, Tiebout, property taxation, and the underprovision of local public goods. Journal of Urban Economics 19(3), 356-370. 